Supporting Information

\title{
Discovery of Tryptanthrins as Novel Antiviral and Anti-phytopathogenic-fungus
}

\section{Agents}

Yanan $\mathrm{Hao}^{\dagger}$, Jincheng $\mathrm{Guo}^{\dagger}$, Ziwen Wang ${ }^{\dagger,}, *$, Yuxiu Liu ${ }^{\dagger, *}$, Yongqiang $\mathrm{Li}^{\dagger}$, Dejun $\mathrm{Ma}^{\dagger}$, Qingmin Wang ${ }^{\dagger} *$

${ }^{\dagger}$ State Key Laboratory of Elemento-Organic Chemistry, Research Institute of Elemento-Organic Chemistry, College of Chemistry, Collaborative Innovation Center of Chemical Science and Engineering (Tianjin), Nankai University, Tianjin 300071, China;

Tianjin Key Laboratory of Structure and Performance for Functional Molecules, College of Chemistry, Tianjin Normal University, Tianjin 300387, China;

Ziwen Wang, Tel: 0086-22-23766531; Fax: 0086-22-23766531; e-mail: hxxywzw@tjnu.edu.cn; Yuxiu Liu, Tel: 0086-22-23503792; Fax: 0086-22-23503792; e-mail: liuyuxiu@nankai.edu.cn; Prof. Qingmin Wang, Tel.: 0086-22-23503952; Fax:0086-22-23503952; e-mail: wangqm@nankai.edu.cn. 


\section{Contents}

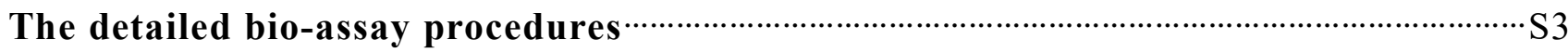

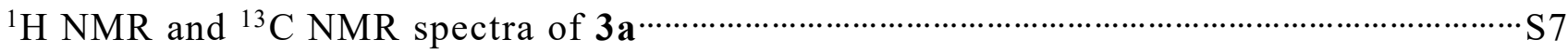

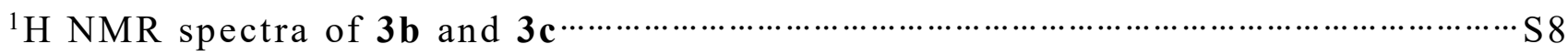

${ }^{1} \mathrm{H}$ NMR spectra of 3d and $\mathbf{3 e}$

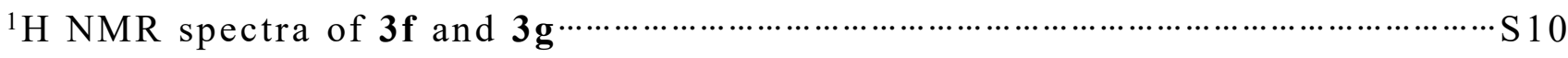

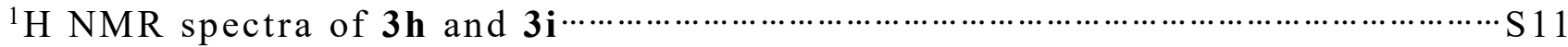

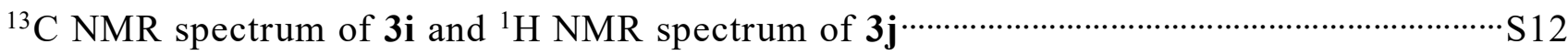

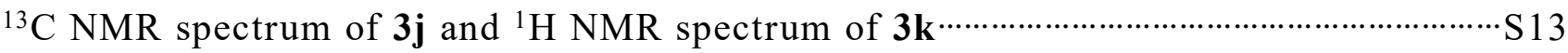

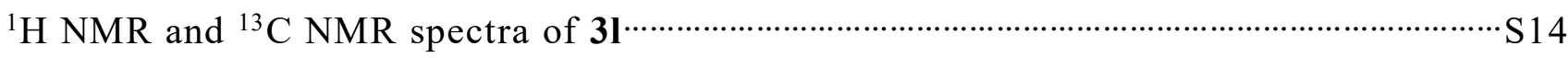

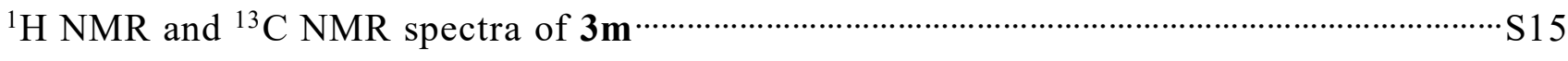

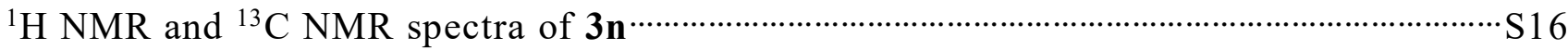

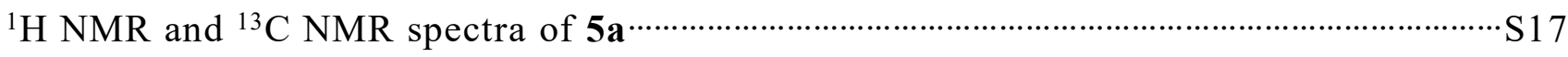

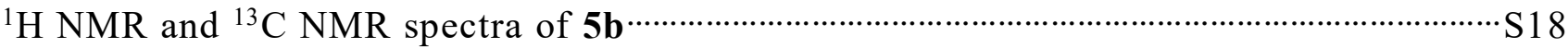

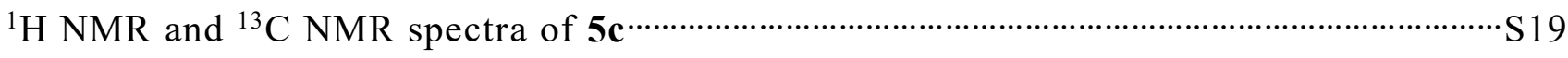

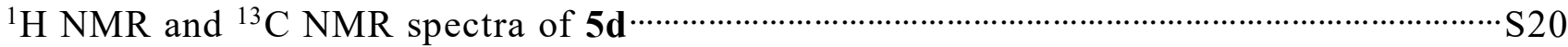

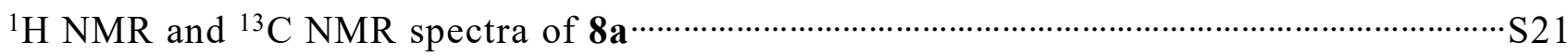

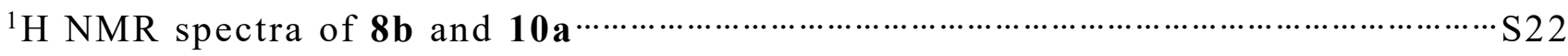

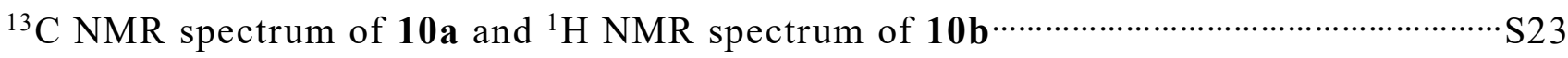

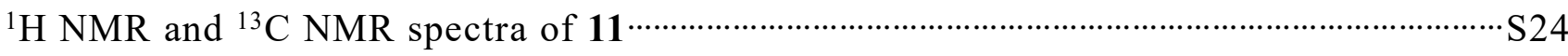

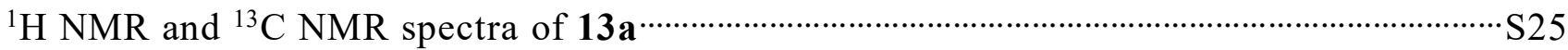

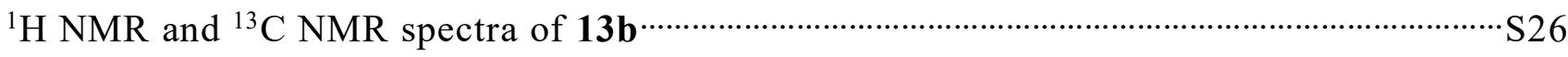

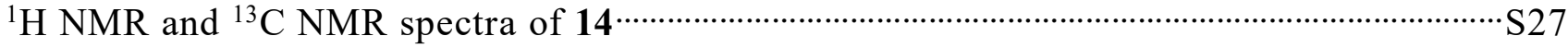

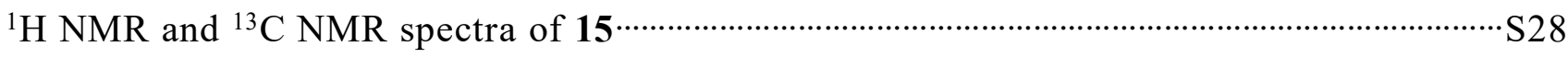

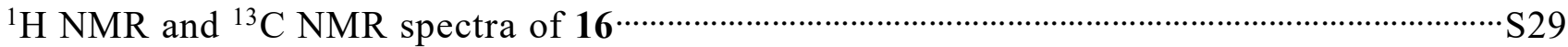

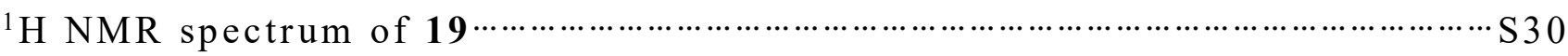




\section{Detailed bio-assay procedures}

Phytotoxic Activity. The phytotoxic activity test was carried out in a climate chamber at a temperature of $25^{\circ} \mathrm{C}$. The growing 3-5 leaf stage tobaccos (Nicotiana tabacum var Xanthi nc) were selected. The compound solution $(100 \mu \mathrm{g} / \mathrm{mL}$ or $500 \mu \mathrm{g} / \mathrm{mL})$ was sprayed on the leaves and then tested the plant height and weight changes after $0,3,7$ and 10 days respectively. There are three replicates for each compound.

\section{Antiviral Biological Assay. ${ }^{1}$}

The antiviral biological assay was carried out in a climate chamber at a temperature of $25^{\circ} \mathrm{C}$.

To prepare the solution of the synthesized compounds or ribavirin, the synthesized compounds or ribavirin were first dissolved within a suitable amount of DMF and diluted with water containing $0.1 \% \mathrm{TW}-80$ to make a concentration of $500 \mu \mathrm{g} / \mathrm{mL}$, and the aqueous solution was diluted to 100 $\mu \mathrm{g} / \mathrm{mL}$.

Purification of Tobacco Mosaic Virus.

Using Gooding's method, ${ }^{2}$ the upper leaves of Nicotiana tabacum L. inoculated with TMV were selected and ground in phosphate buffer and then filtered through double-layer pledget. The filtrate was centrifuged at $10000 \mathrm{~g}$, treated with PEG twice, and centrifuged again. The whole experiment was processed at $4{ }^{\circ} \mathrm{C}$. Absorbance value was estimated at $260 \mathrm{~nm}$ by ultraviolet spectrophotometer.

$$
\text { Virus conch }=\left(A_{260} \times \text { dilution ratio }\right) E /_{1 \mathrm{~cm}}^{0.1 \%, 260 \mathrm{~nm}}
$$

\section{Protective Effect of Compounds against TMV in Vivo.}

The solution $(100 \mu \mathrm{g} / \mathrm{mL}$ or $500 \mu \mathrm{g} / \mathrm{mL})$ of synthesized compounds or ribavirin was sprayed on growing Nicotiana. tabacum L. leaves (at least 3 leaves) of the same age. In another pot, the leaves were sprayed with the solvent as a control. The leaves were then inoculated with the virus $\left(6 \times 10^{-3}\right.$ 
$\mu \mathrm{g} / \mathrm{mL}$ ) after $12 \mathrm{~h}$ by rubbing emery. First, spread a layer of 600 mesh emery on the tested leaves, then brush the leaves 1 to 2 times along the direction of the vein with a brush stained with TMV $(6 \times$ $10^{-3} \mu \mathrm{g} / \mathrm{mL}$ ), and then wash the leaves with clear water. The total local lesion numbers appearing on the leaves 3-4 days after inoculation were recorded. ${ }^{3}$ There are three replicates for each test. Inactivation Effect of Compounds against TMV in Vivo.

To test viral inhibition, equal volumes of the virus $\left(6 \times 10^{-3} \mu \mathrm{g} / \mathrm{mL}\right)$ and the solution $(100 \mu \mathrm{g} / \mathrm{mL}$ or $500 \mu \mathrm{g} / \mathrm{mL}$ ) of synthesized compounds or ribavirin were mixed together for $30 \mathrm{~min}$. The mixture was then inoculated into the growing $N$. tabacum L leaves of the same age by rubbing emery, and another pot was inoculated with the mixture of solvent and the virus $\left(6 \times 10^{-3} \mu \mathrm{g} / \mathrm{mL}\right)$ by rubbing emery as the control. Then, the leaves were washed with water and dried. The local lesion numbers were recorded 3-4 days after inoculation. ${ }^{3}$ There are three replicates for each compound.

\section{Curative Effect of Compounds against TMV in Vivo.}

TMV (concentration of $6.0 \times 10^{-3} \mu \mathrm{g} / \mathrm{mL}$ ) was inoculated on the growing leaves of $N$. tabacum L. of the same age by rubbing emery. Then, the leaves were washed with water and dried. The solution $(100 \mu \mathrm{g} / \mathrm{mL}$ or $500 \mu \mathrm{g} / \mathrm{mL})$ of synthesized compounds or ribavirin was smeared on the inoculated leaves, while inoculated leaves in another pot were smeared with the solvent as a control. The local lesion numbers were recorded 3-4 days after inoculation. ${ }^{3}$ There are three replicates for each test.

The in vivo inhibition rates were then calculated according to the following formula ("av" means average, and controls were not treated with compound).

Inhibition rate $(\%)=[($ av local lesion no. of control - av local lesion no. of drug-treated $) /$ av local lesion no. of control] $\times 100 \%$

\section{Mode of Action Studies.}

In vitro TMV rod assembly inhibition : TMV purification was performed according to the 
instructions by Leberman. ${ }^{4}$ TMV RNA was purified by RNApure virus kit (CoWin Biosciences) and TMV capsid protein (TMV CP) was isolated using glacial acetic acid as described by Fraenkel-Conrat. ${ }^{5}$ Before assembly, 20S CP Disk was prepared by incubating $20 \mathrm{mg} / \mathrm{mL}$ TMV CP in $0.1 \mathrm{M}$ phosphate buffer $(\mathrm{pH} 7.0)$ at $20{ }^{\circ} \mathrm{C}$ for $12 \mathrm{~h}$. After incubation, in vitro TMV reconstitution reactions were performed by adding $5 \mu \mathrm{L}$ of phosphate buffer $(0.1 \mathrm{M}, \mathrm{pH} 7.0), 4 \mu \mathrm{L}$ of $20 \mathrm{~S}$ Disk (2 $\mathrm{mg} / \mathrm{mL})$ and $1 \mu \mathrm{L}$ of TMV RNA $(200 \mathrm{ng} / \mu \mathrm{L})$. The assembly reaction mixture was incubated at $20{ }^{\circ} \mathrm{C}$ for $12 \mathrm{~h}$ and could be then transferred into the copper grid for transmission electron microscopy (TEM) assay. The assembly reaction mixture $(5 \mu \mathrm{L})$ was mixed with $5 \mu \mathrm{L} 0.1 \mathrm{M}$ phosphate buffer (pH 7.0) and dropped onto the copper film waiting for 5 minutes. After the incubation, the droplet was removed by filter paper and negatively stained by $2 \%$ phosphotungstic acid $(\mathrm{pH} 7.0)$ for three minutes. After removing the staining agent, the copper was placed at $37{ }^{\circ} \mathrm{C}$ for $2 \mathrm{~h}$ for drying. The morphology of the reconstituted TMV rods was imaged at $200 \mathrm{keV}$ on a CCD camera. For the inhibition tests with the compounds, in vitro TMV reconstitution inhibition reactions were performed by adding $4.8 \mu \mathrm{L}$ of phosphate buffer $(0.1 \mathrm{M}, \mathrm{pH} 7.0), 4 \mu \mathrm{L}$ of $20 \mathrm{~S}$ Disk $(2 \mathrm{mg} / \mathrm{mL}), 1 \mu \mathrm{L}$ of TMV RNA $(200 \mathrm{ng} / \mu \mathrm{L})$ and $0.2 \mu \mathrm{L}$ of DMSO or the compound $(10 \mu \mathrm{M})$. All treatments were repeated over time to validate the results.

In vitro 20S CP Disk assembly inhibition: For the inhibition tests with the compounds, TMV CP was first adjusted to $20.4 \mathrm{mg} / \mathrm{mL}$ with $0.1 \mathrm{M}$ phosphate buffer (pH 7.0). In vitro 20S CP Disk assembly reactions were performed by adding $9.8 \mu \mathrm{L}$ TMV CP $(20.4 \mathrm{mg} / \mathrm{mL})$ and $0.2 \mu \mathrm{L}$ DMSO or the compound $(10 \mu \mathrm{M})$. The assembly reaction was incubated at $20^{\circ} \mathrm{C}$ for $12 \mathrm{~h}$. The morphology of the 20S CP Disk was imaged via TEM at $200 \mathrm{keV}$ on a CCD camera. All treatments were repeated over time for confirmation. 


\section{Detailed bioassay procedures for the fungicidal activities ${ }^{6}$}

In Vitro Antifungal Bioassay. The fungicidal activities of compounds were evaluated in mycelial growth tests conducted in artificial media against 14 plant pathogens at a rate of $50 \mu \mathrm{g} / \mathrm{mL}$. Each test compound was dissolved in a suitable amount of acetone and diluted with water containing $0.1 \%$ TW-80 to a concentration of $500 \mu \mathrm{g} / \mathrm{mL}$. To each petri dish was added $1 \mathrm{~mL}$ of the test solution and $9 \mathrm{~mL}$ of culture medium to make a $50 \mu \mathrm{g} / \mathrm{mL}$ concentration of the test compound, while in another petri dish was added $1 \mathrm{~mL}$ distilled water containing 0.1\% TW-80 and $9 \mathrm{~mL}$ of culture medium as a blank control. A $4 \mathrm{~mm}$ diameter of hyphal growth was cut using a hole puncher on a growing fungal culture and the hyphae were moved to the petri dish containing the test compound. Each assay was performed three times. The dishes were stored in controlled environment cabinets $\left(24 \pm 1^{\circ} \mathrm{C}\right)$ for 4 days, after which the diameter of mycelial growth was measured and the percentage inhibition was calculated using the following equation: Percentage inhibition $(\%)=($ averaged diameter of mycelia in blank controls - averaged diameter of mycelia in medicated tablets) / (averaged diameter of mycelia in blank controls $-4 \mathrm{~mm}) \times 100$.

\section{Reference:}

(1) Wang, Z. W.; Wei, P.; Wang, L. Z.; Wang, Q. M. Design, synthesis, and anti-tobacco mosaic virus (TMV) activity of phenanthroindolizidines and their analogues. J. Agric. Food Chem. 2012, 60, 10212-10219.

(2) Gooding, G. V., Jr.; Hebert, T. T. A simple technique for purification of tobacco mosaic virus in large quantities. Phytopathology 1967, 57, 1285-1290.

(3) Li, S. Z.; Wang, D. M.; Jiao, S. M. In Pesticide Experiment Methods-Fungicide Sector; Li, S. Z., Ed.; Agriculture Press of China: Beijing, China, 1991; 93-94.

(4) Leberman, R. Isolation of plant viruses by means of simple coacervates. Virol 1966, 30, 341-347.

(5) Fraenkel Conrat, H.; Williams, R. C. Reconstitution of active tobacco mosaic virus fromits inactive protein and nucleic acid components. Proc Natl Acad Sci U S A 1955, 41, 690-698.

(6) Zhao, H. P.; Liu, Y. X.; Cui, Z. P.; Beattie, D.; Gu, Y. C.; Wang, Q. M. Design, synthesis, and biological activities of arylmethylamine substituted chlorotriazine and methylthiotriazine compounds. J. Agric. Food Chem. 2011, 59, 11711-11717. 


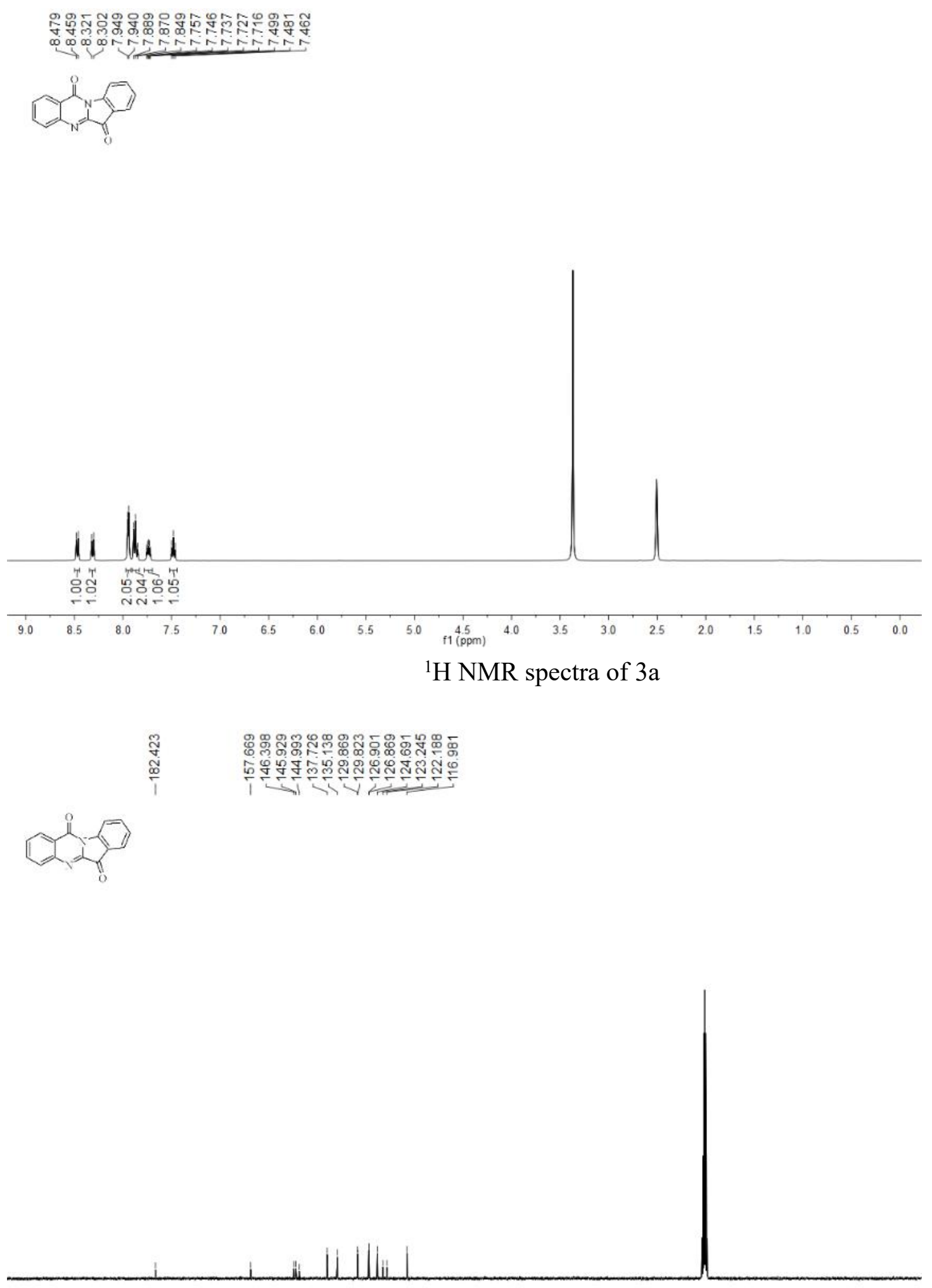

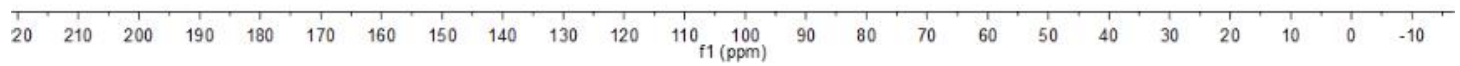
${ }^{13} \mathrm{C}$ NMR spectra of $3 \mathrm{a}$ 


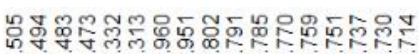

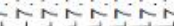

(1)

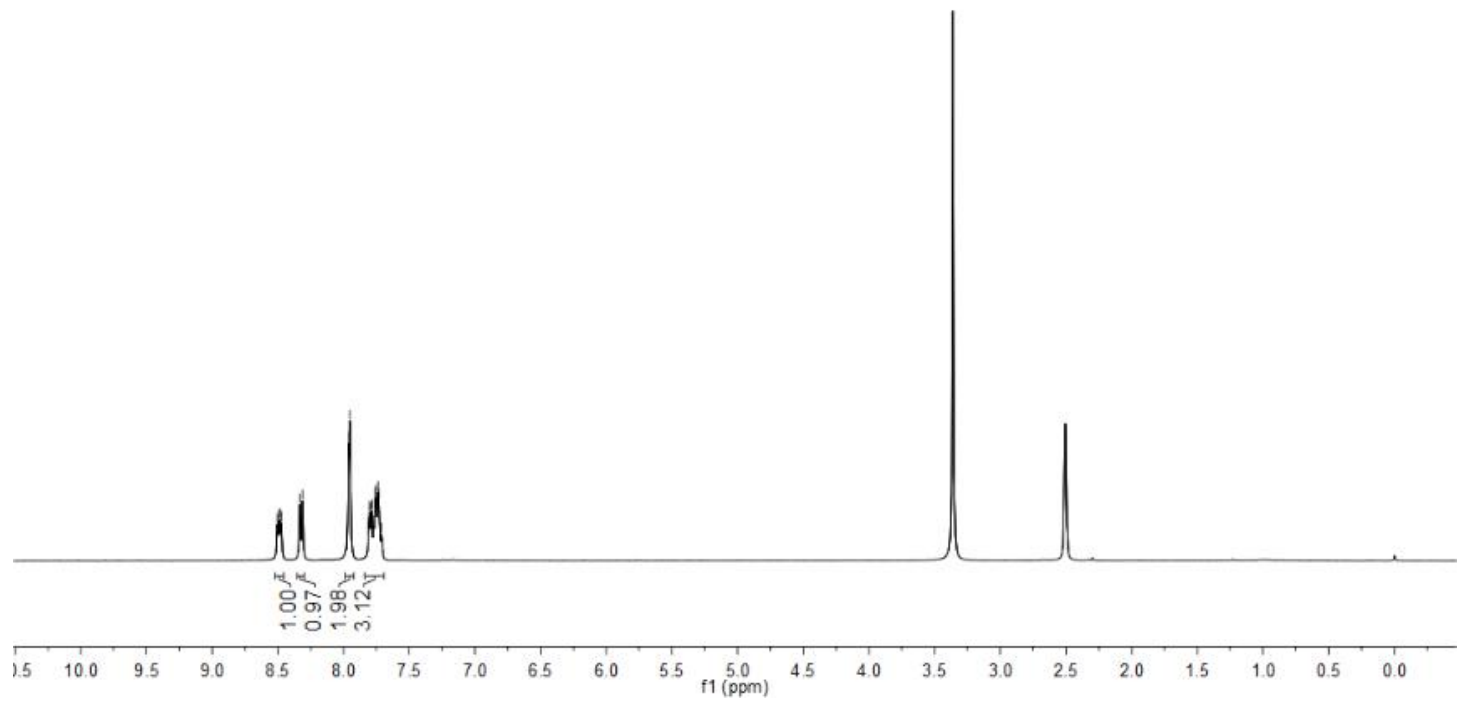

${ }^{1} \mathrm{H}$ NMR spectra of $3 \mathrm{~b}$

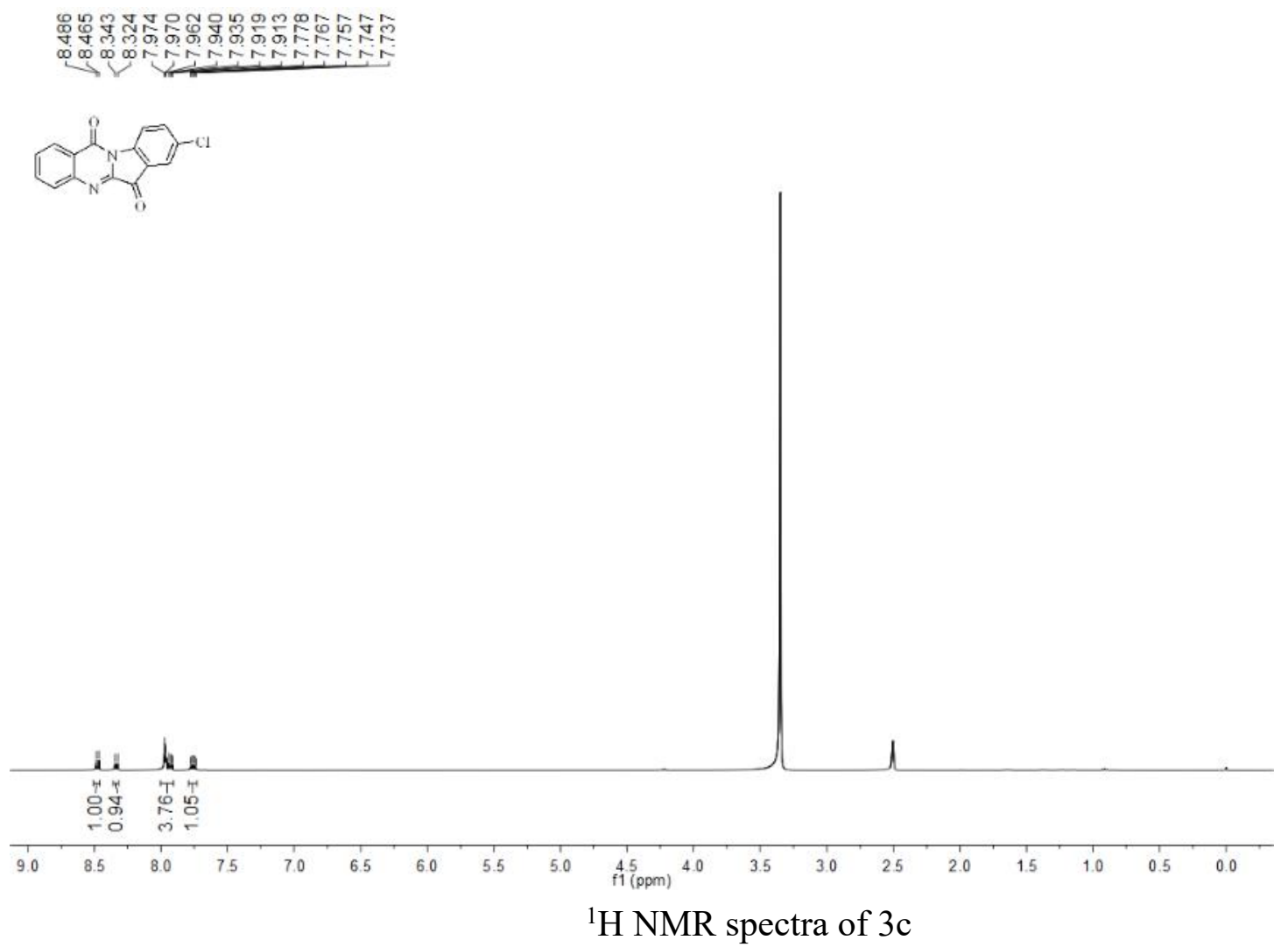




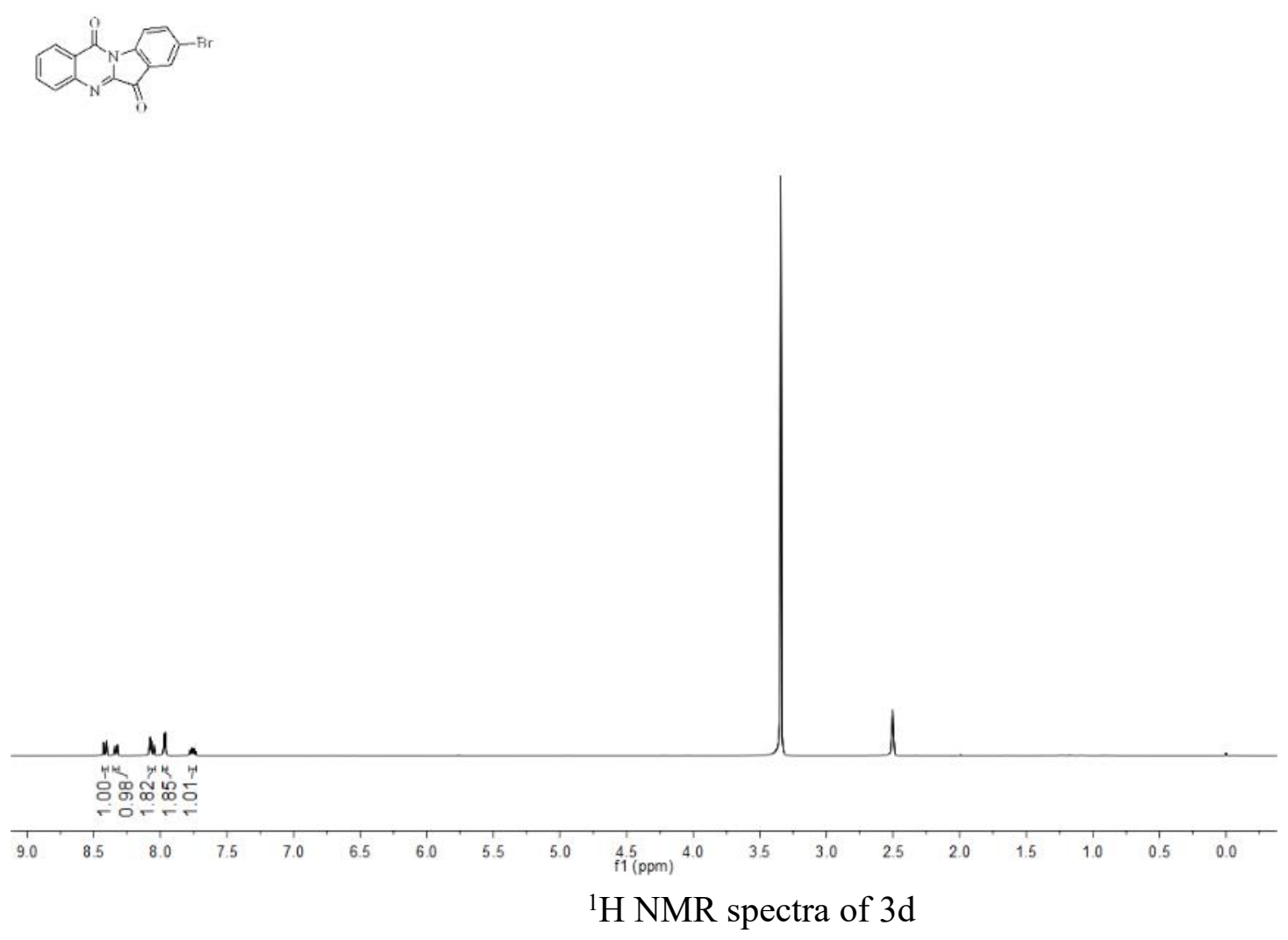

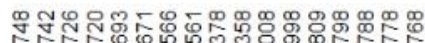

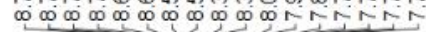

$\left({ }_{\mathrm{N}}\right.$

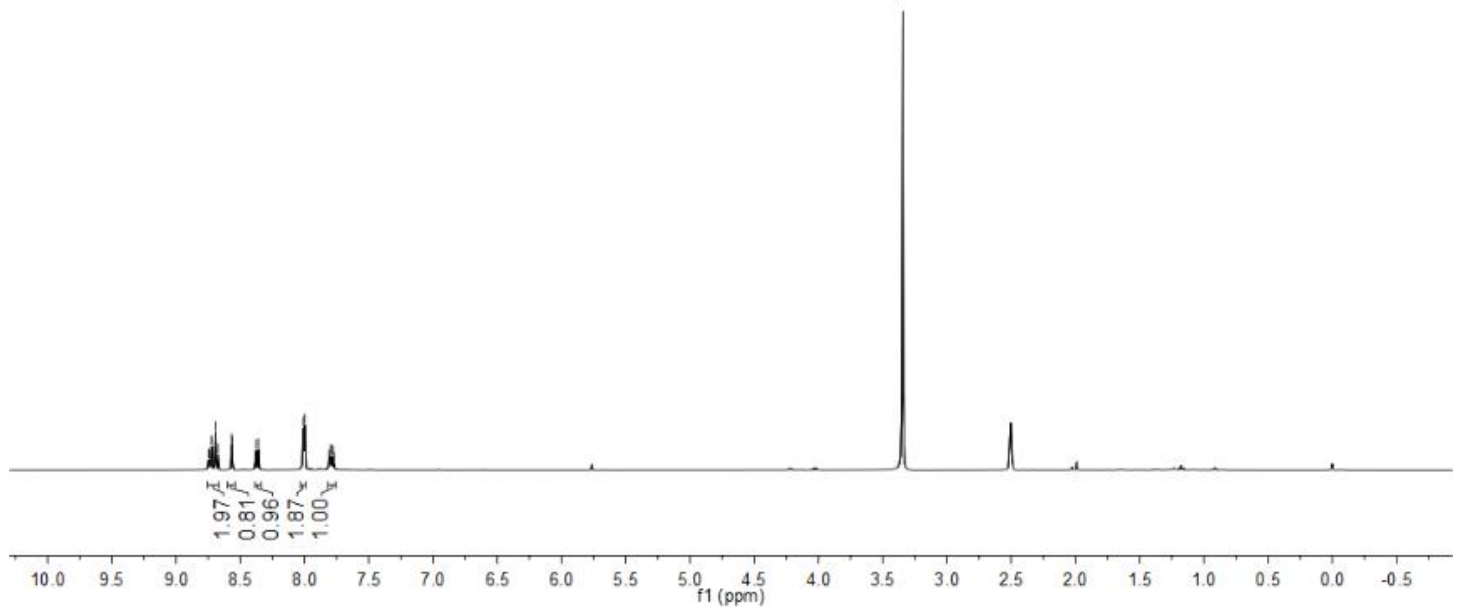

${ }^{1} \mathrm{H}$ NMR spectra of $3 \mathrm{e}$ 


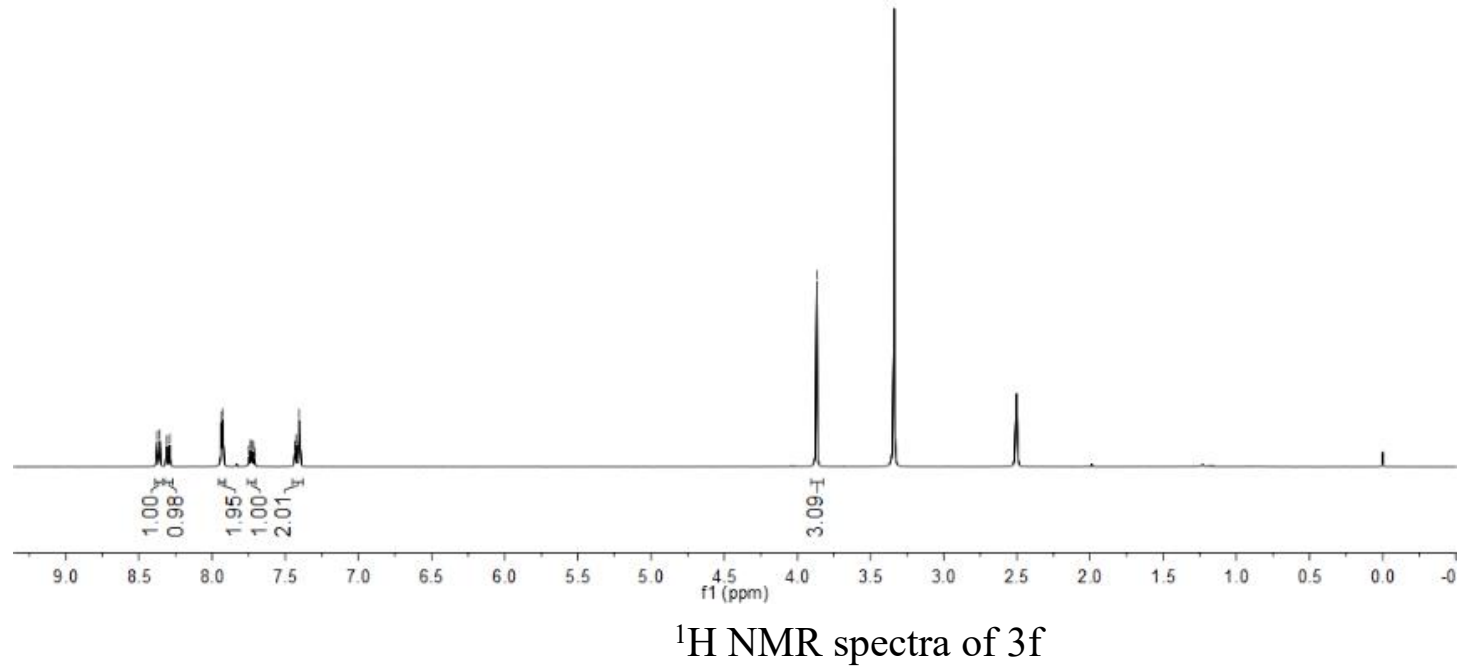

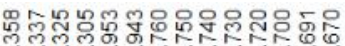

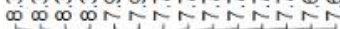
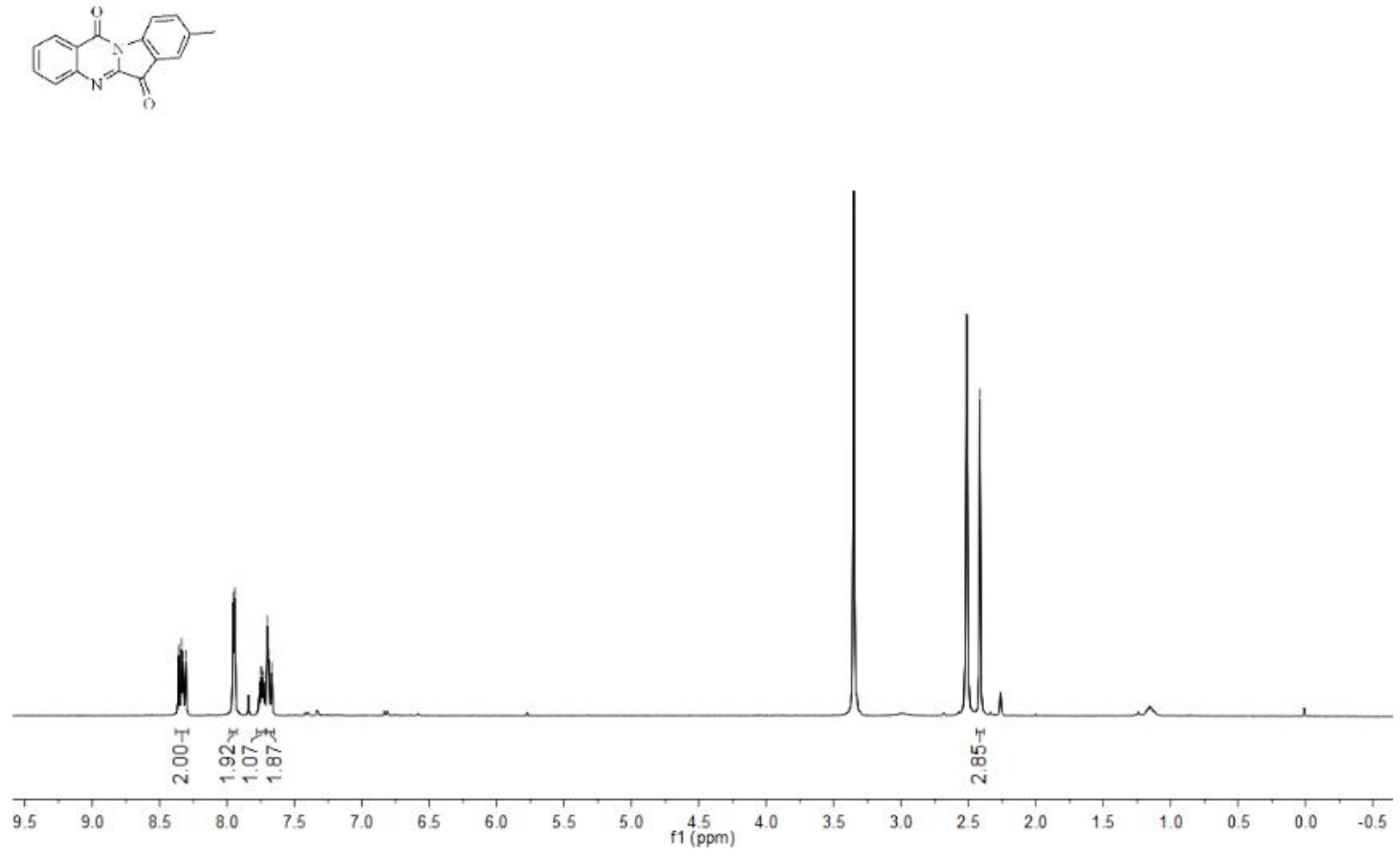

${ }^{1} \mathrm{H}$ NMR spectra of $3 \mathrm{~g}$ 

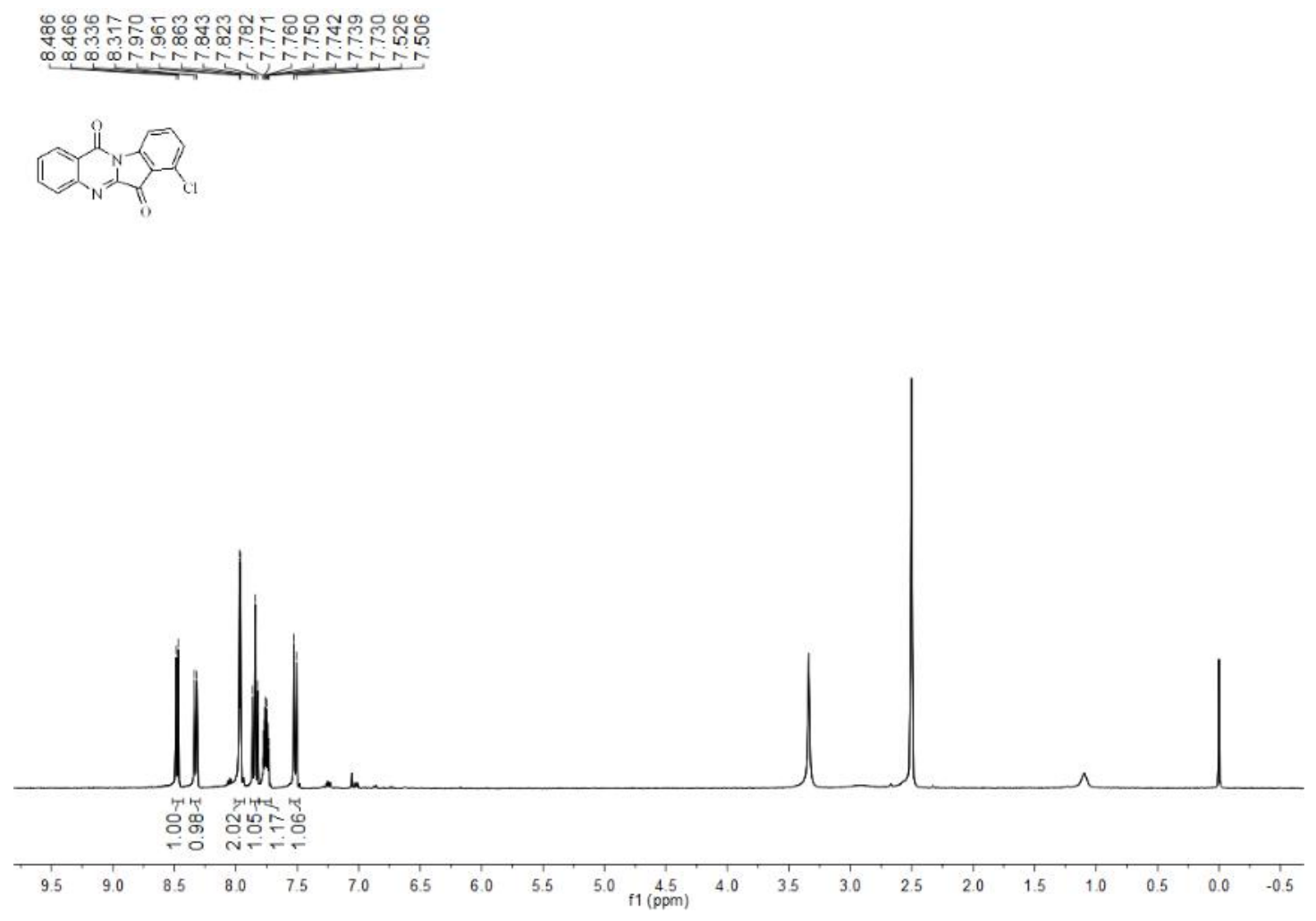

${ }^{1} \mathrm{H}$ NMR spectra of $3 \mathrm{~h}$
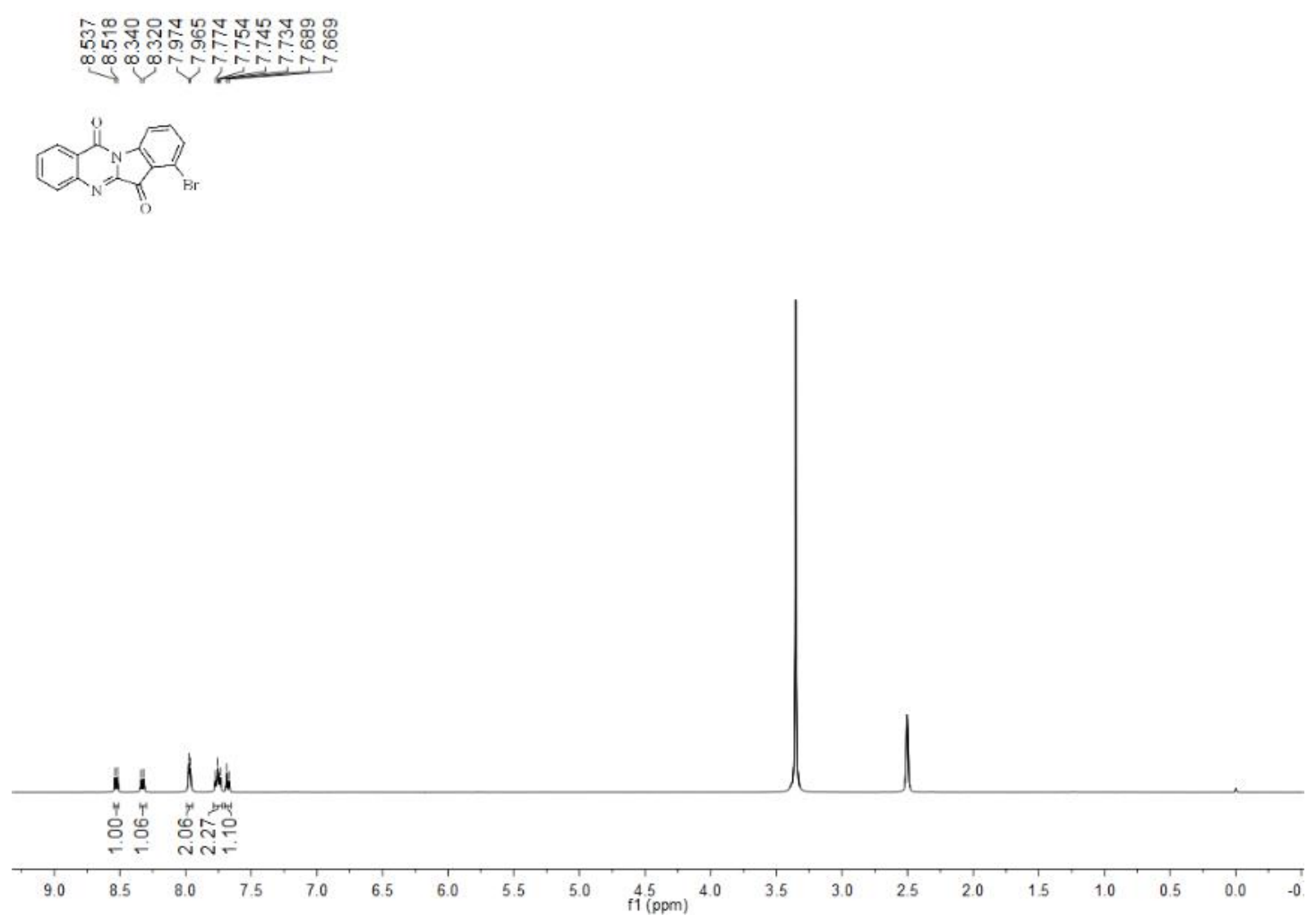

${ }^{1} \mathrm{H}$ NMR spectra of $3 \mathrm{i}$ 

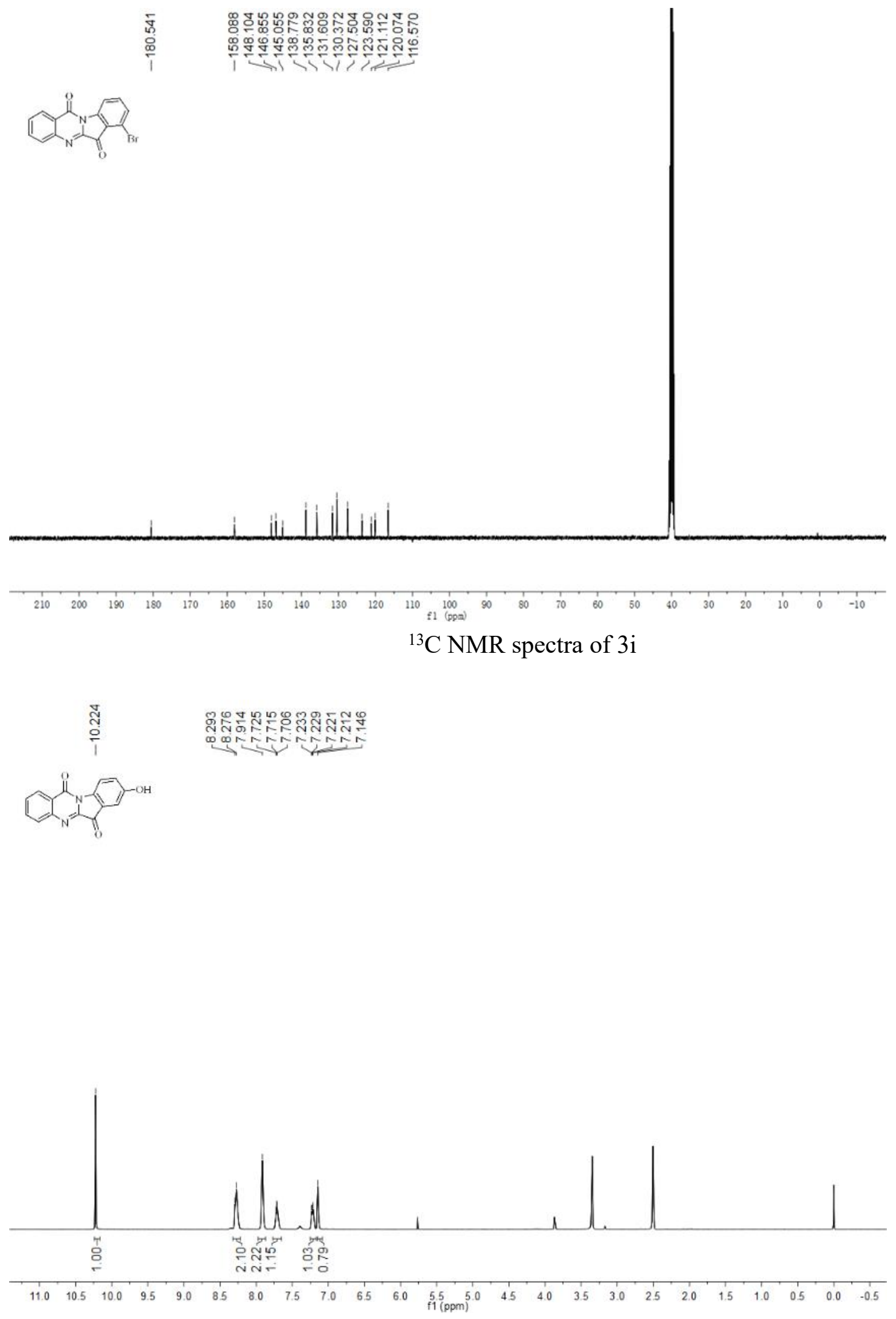

${ }^{1} \mathrm{H}$ NMR spectra of $3 \mathrm{j}$ 

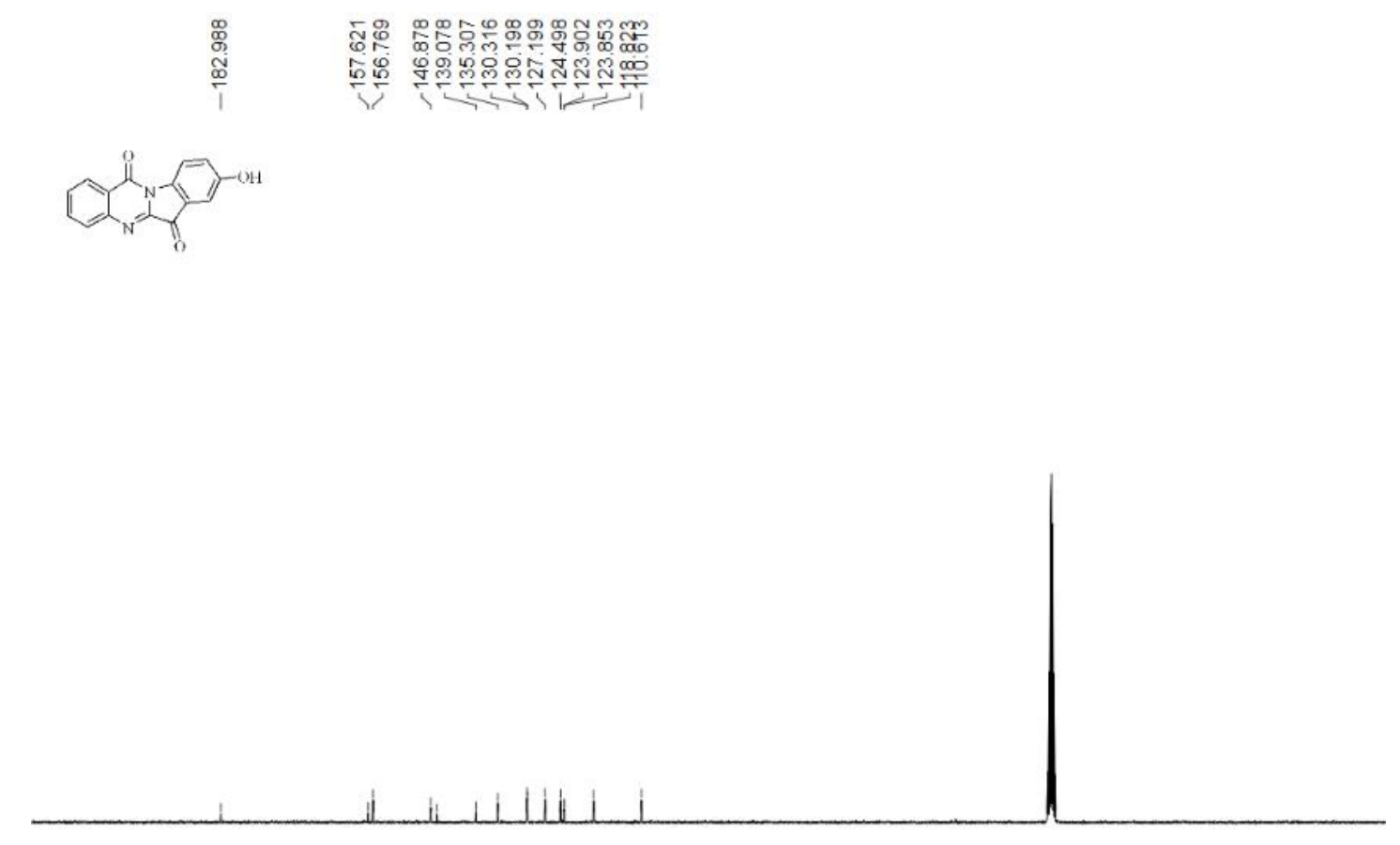

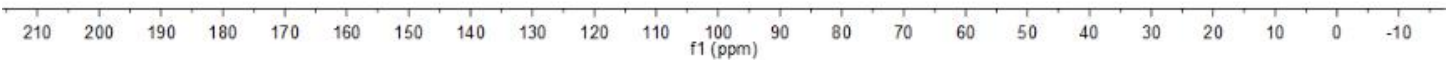

${ }^{13} \mathrm{C} \mathrm{NMR}$ spectra of $3 \mathrm{j}$
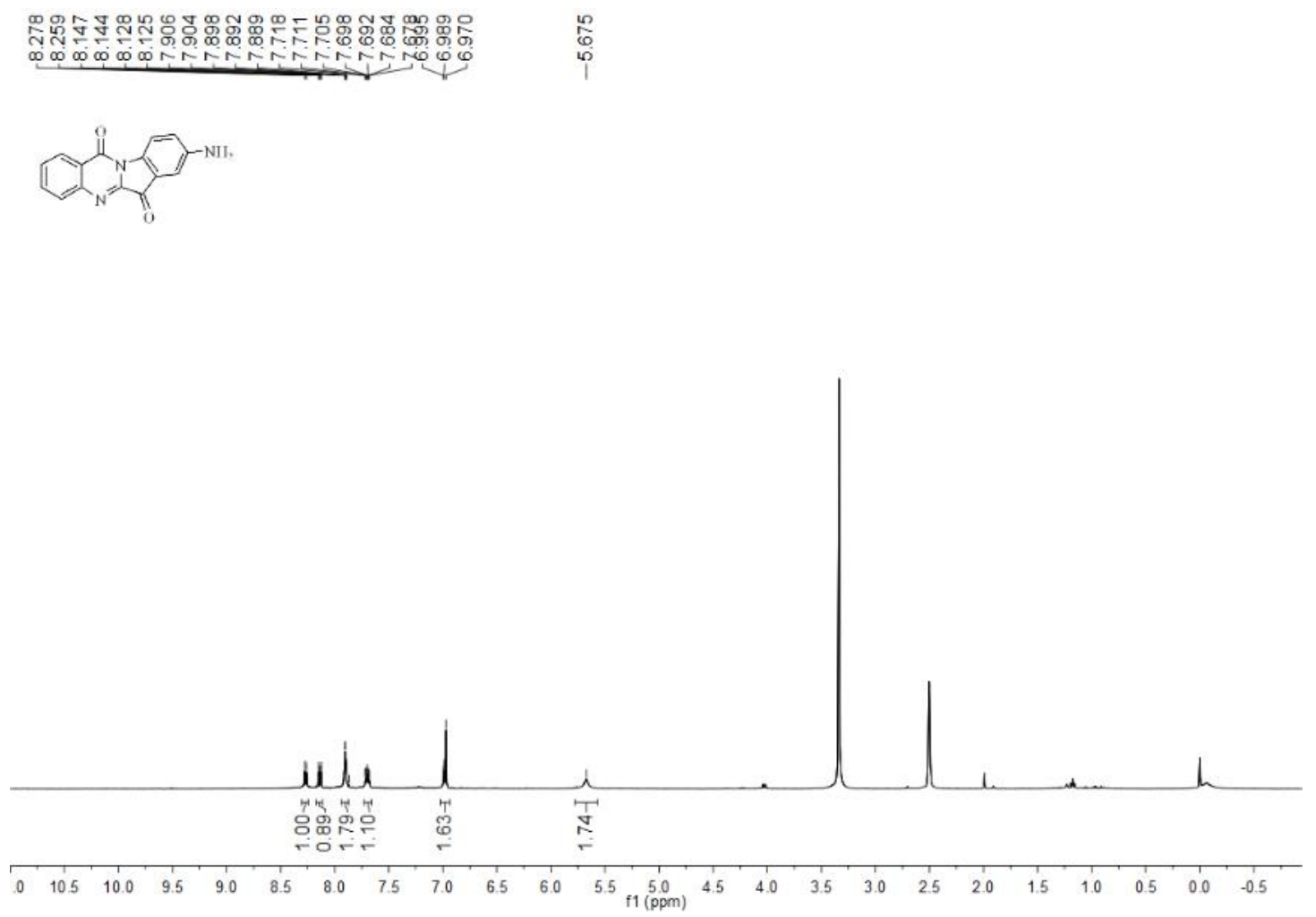

${ }^{1} \mathrm{H}$ NMR spectra of $3 \mathrm{k}$ 

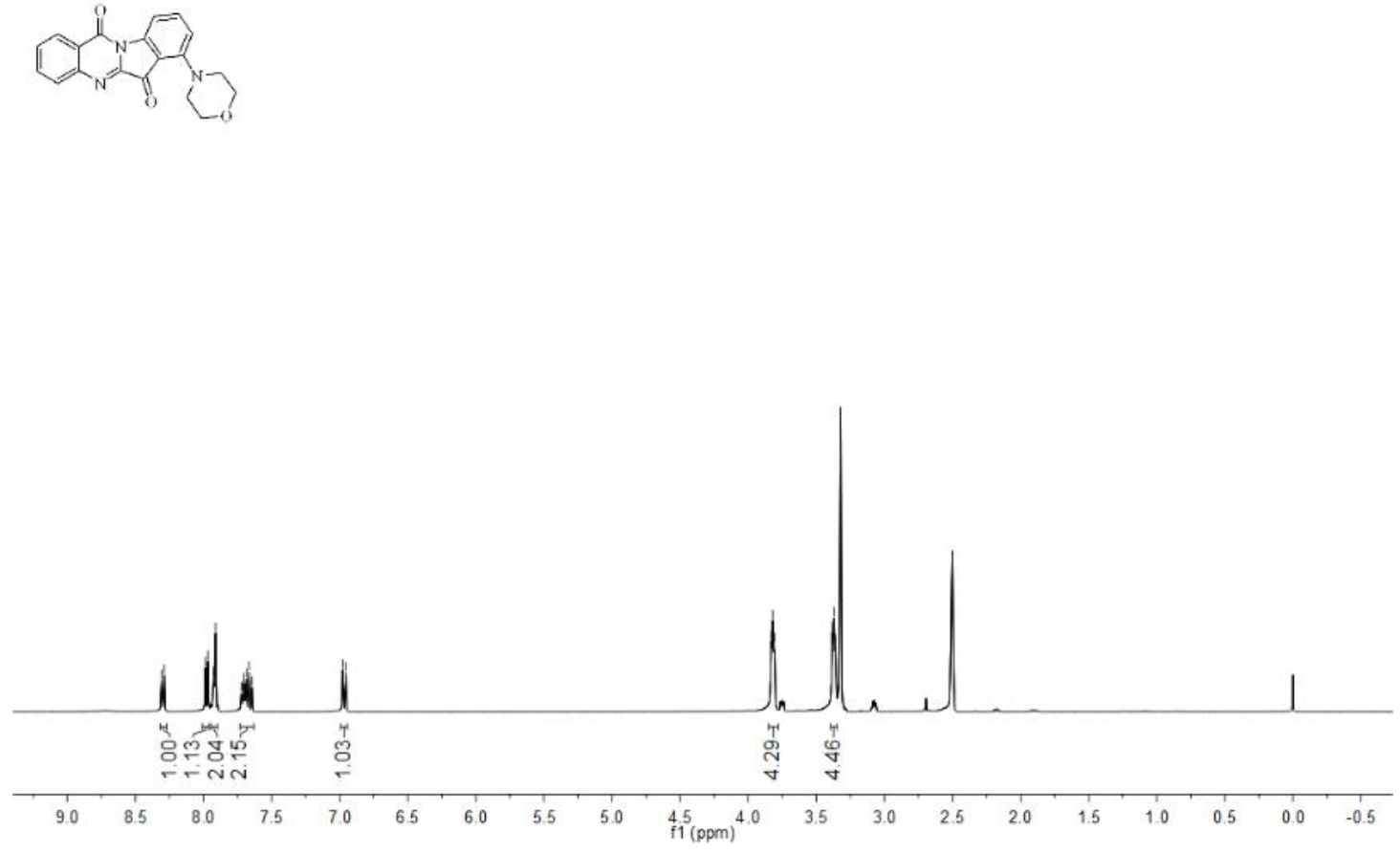

${ }^{1} \mathrm{H}$ NMR spectra of 31
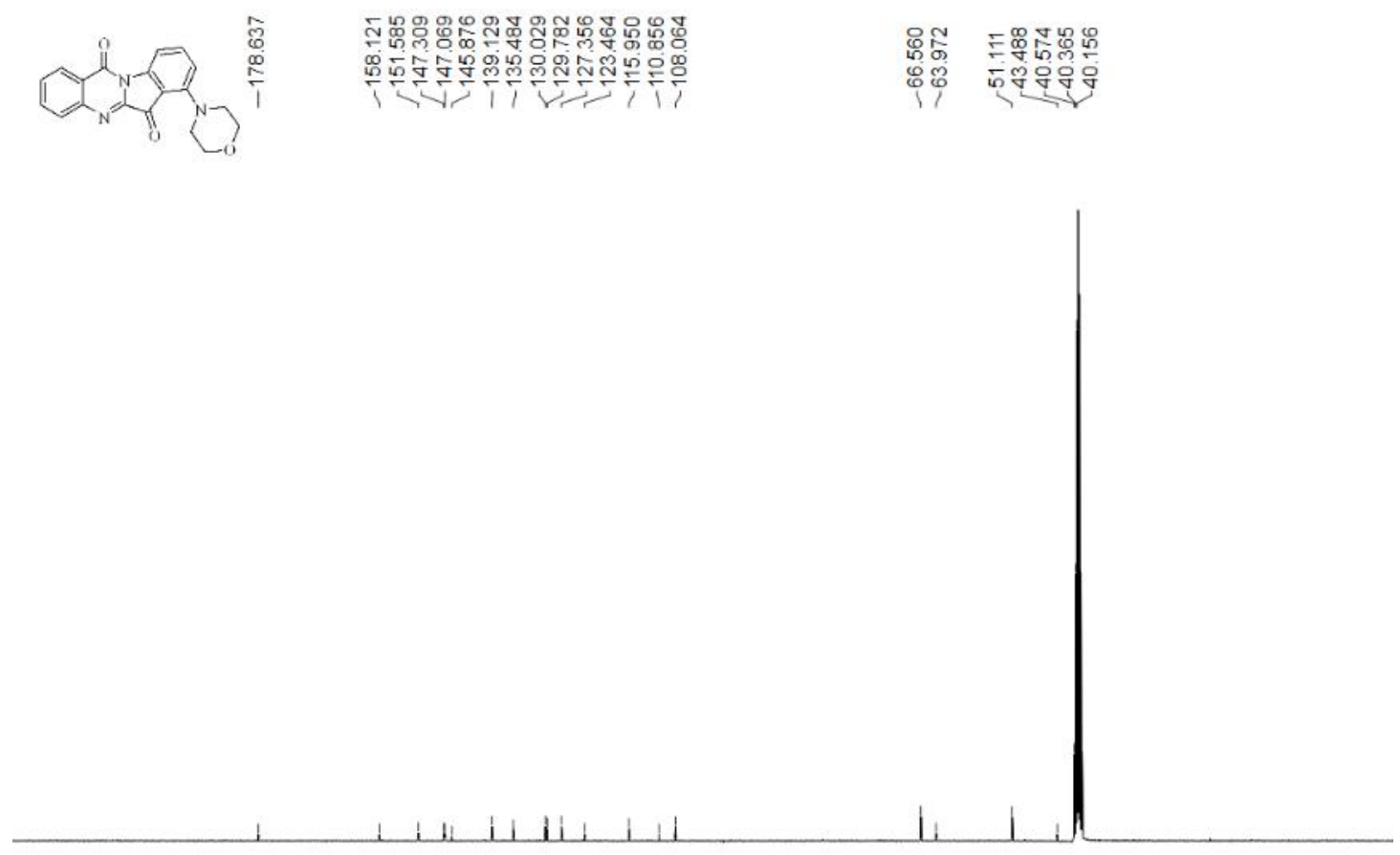

$\begin{array}{lllllllllllllllllllllllllll}20 & 210 & 200 & 190 & 180 & 170 & 160 & 150 & 140 & 130 & 120 & \begin{array}{l}110 \\ \mathrm{f} 1(\mathrm{pom})\end{array} & 100 & 80 & 70 & 60 & 50 & 40 & 30 & 20 & 10 & 0 & -10\end{array}$ ${ }^{13} \mathrm{C}$ NMR spectra of 31 


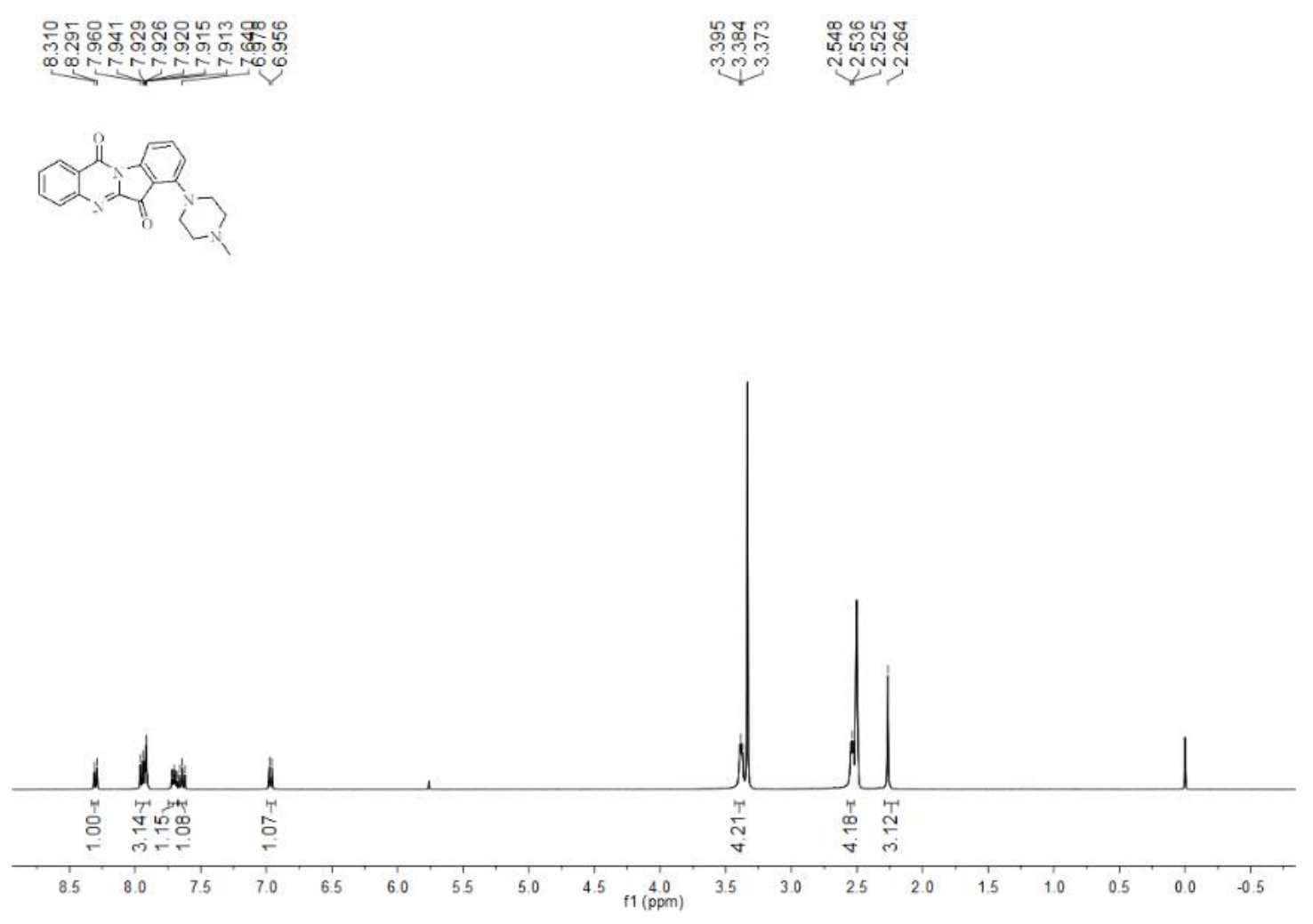

${ }^{1} \mathrm{H}$ NMR spectra of $3 \mathrm{~m}$
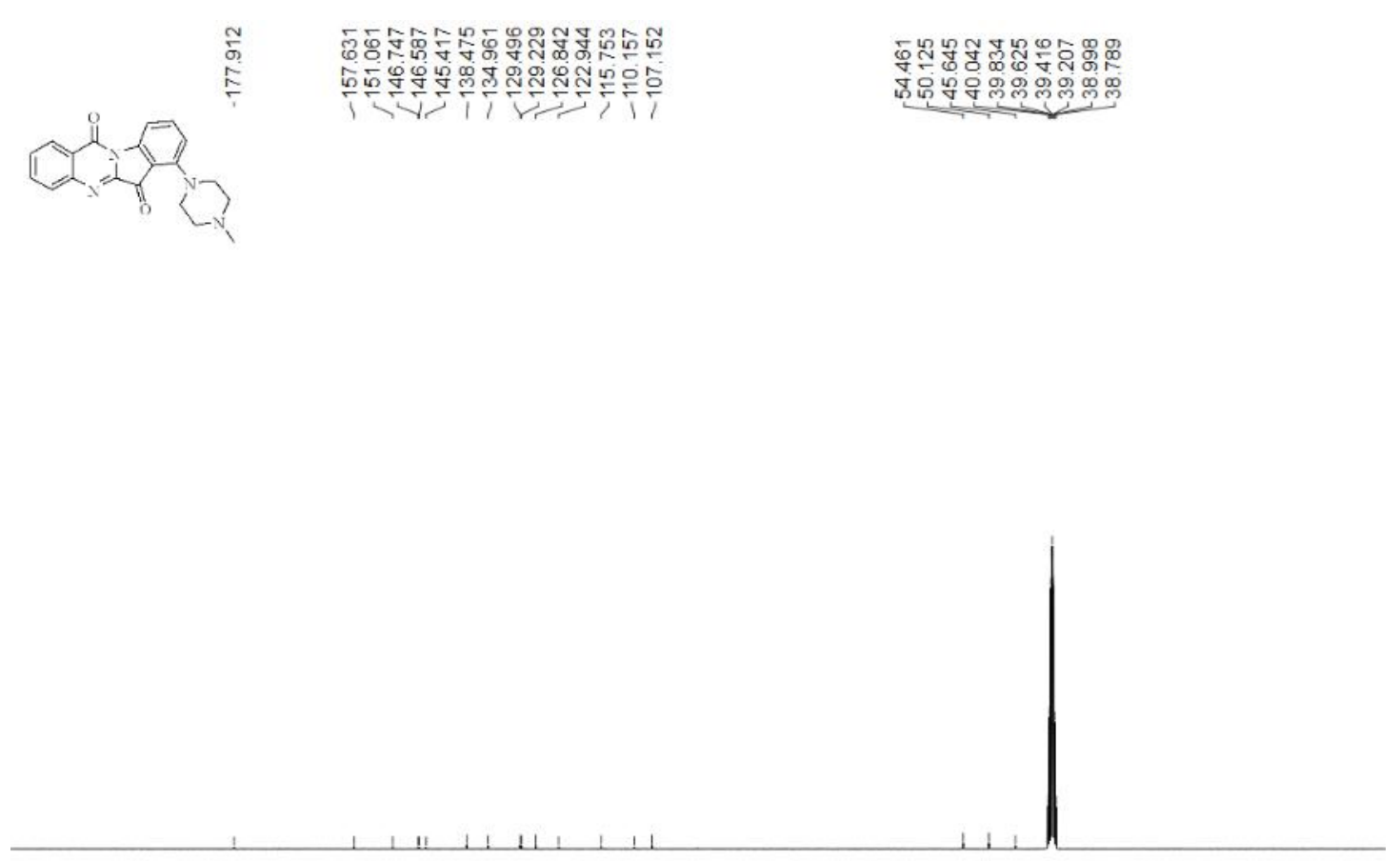

\begin{tabular}{|lllllllllllllllllllllllll}
\hline 210 & 200 & 190 & 180 & 170 & 160 & 150 & 140 & 130 & 120 & 110 & 100 & 90 & 80 & 70 & 60 & 50 & 40 & 30 & 20 & 10 & 0 & -10 \\
\hline
\end{tabular}

${ }^{13} \mathrm{C}$ NMR spectra of $3 \mathrm{~m}$ 


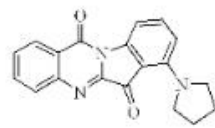
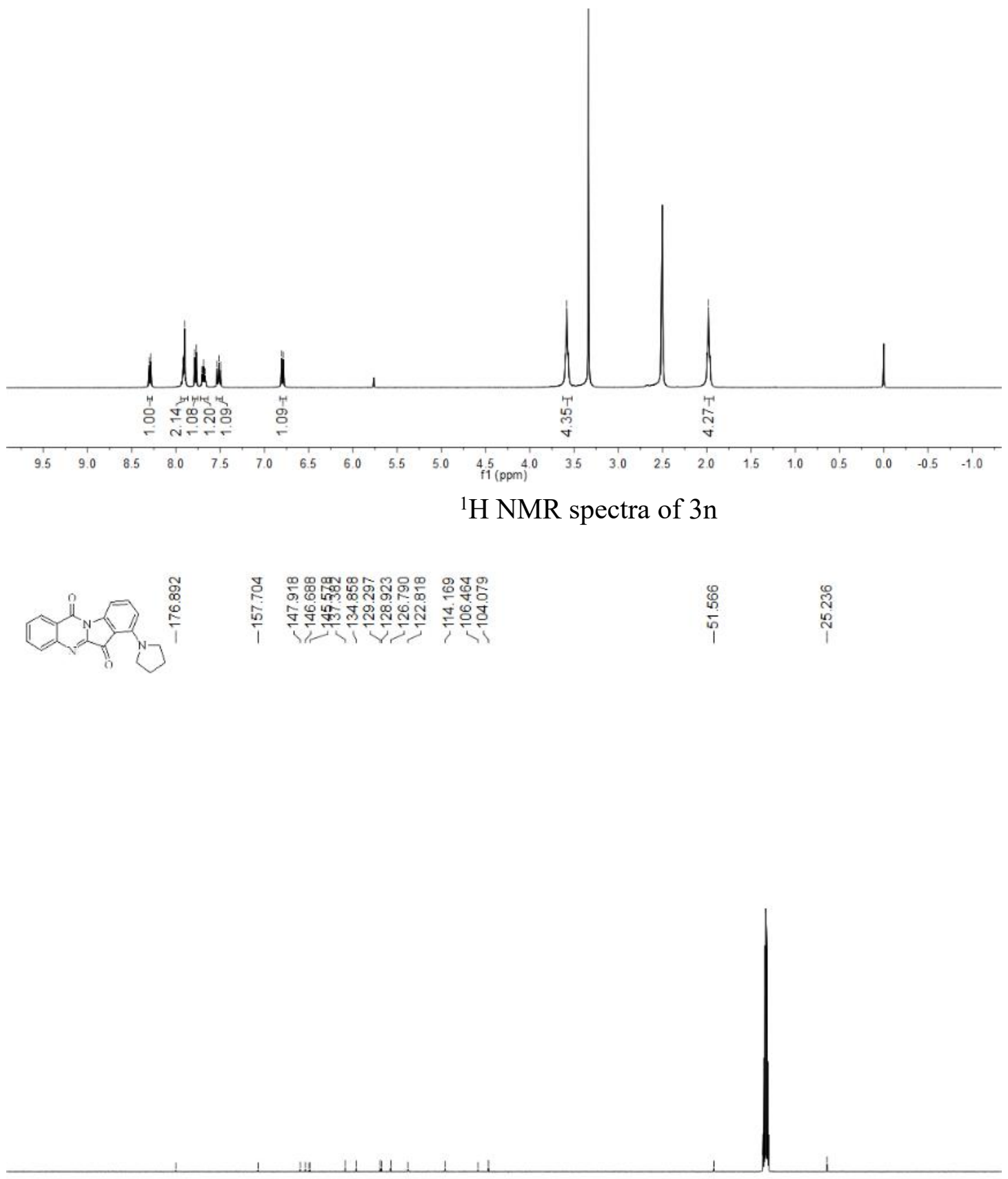

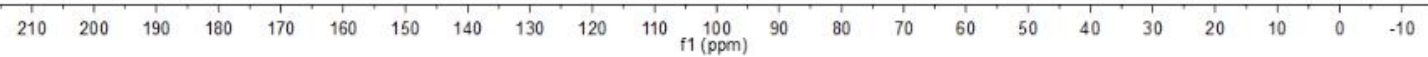

${ }^{13} \mathrm{C}$ NMR spectra of $3 \mathrm{n}$ 

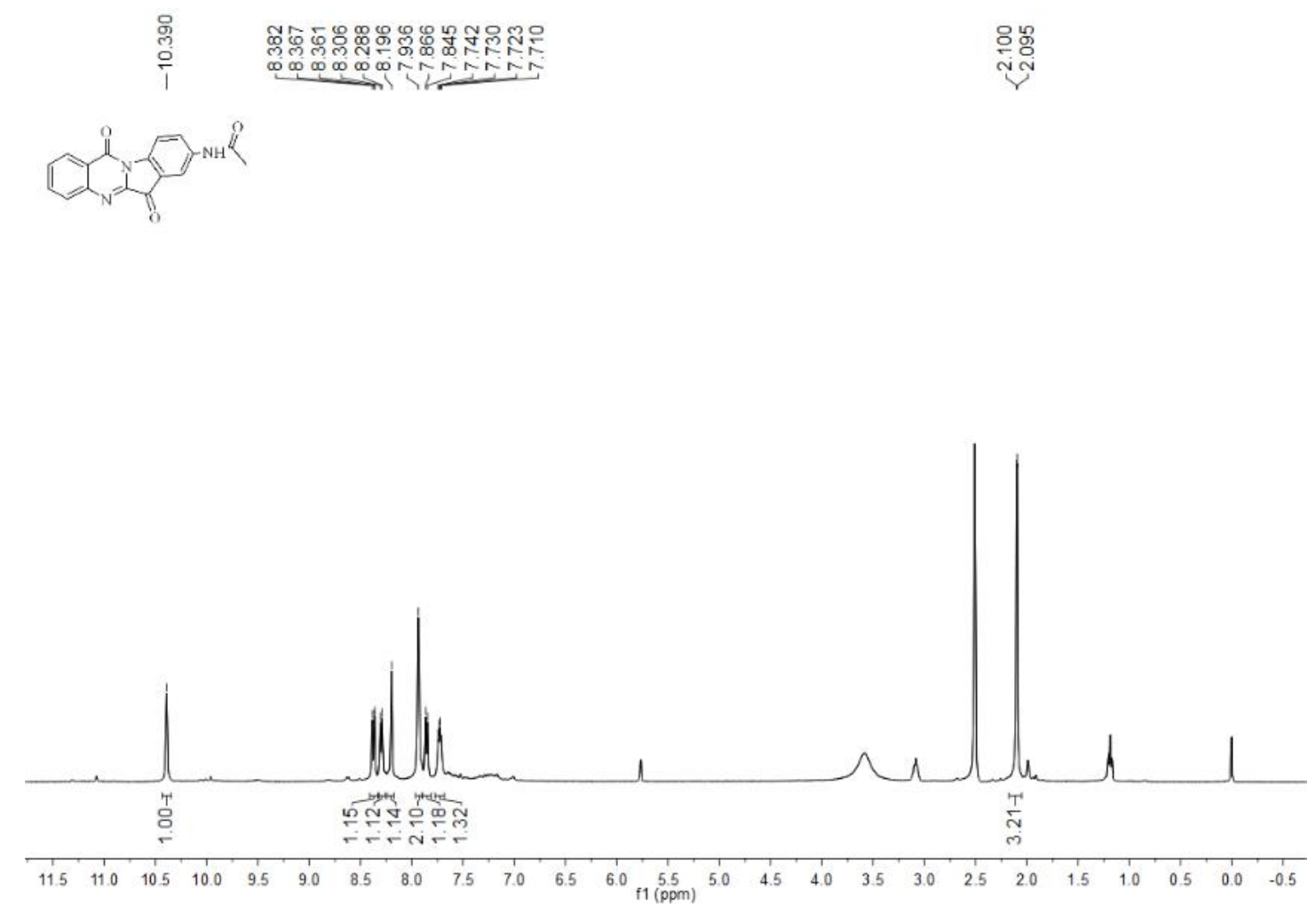

${ }^{1} \mathrm{H}$ NMR spectra of $5 \mathrm{a}$
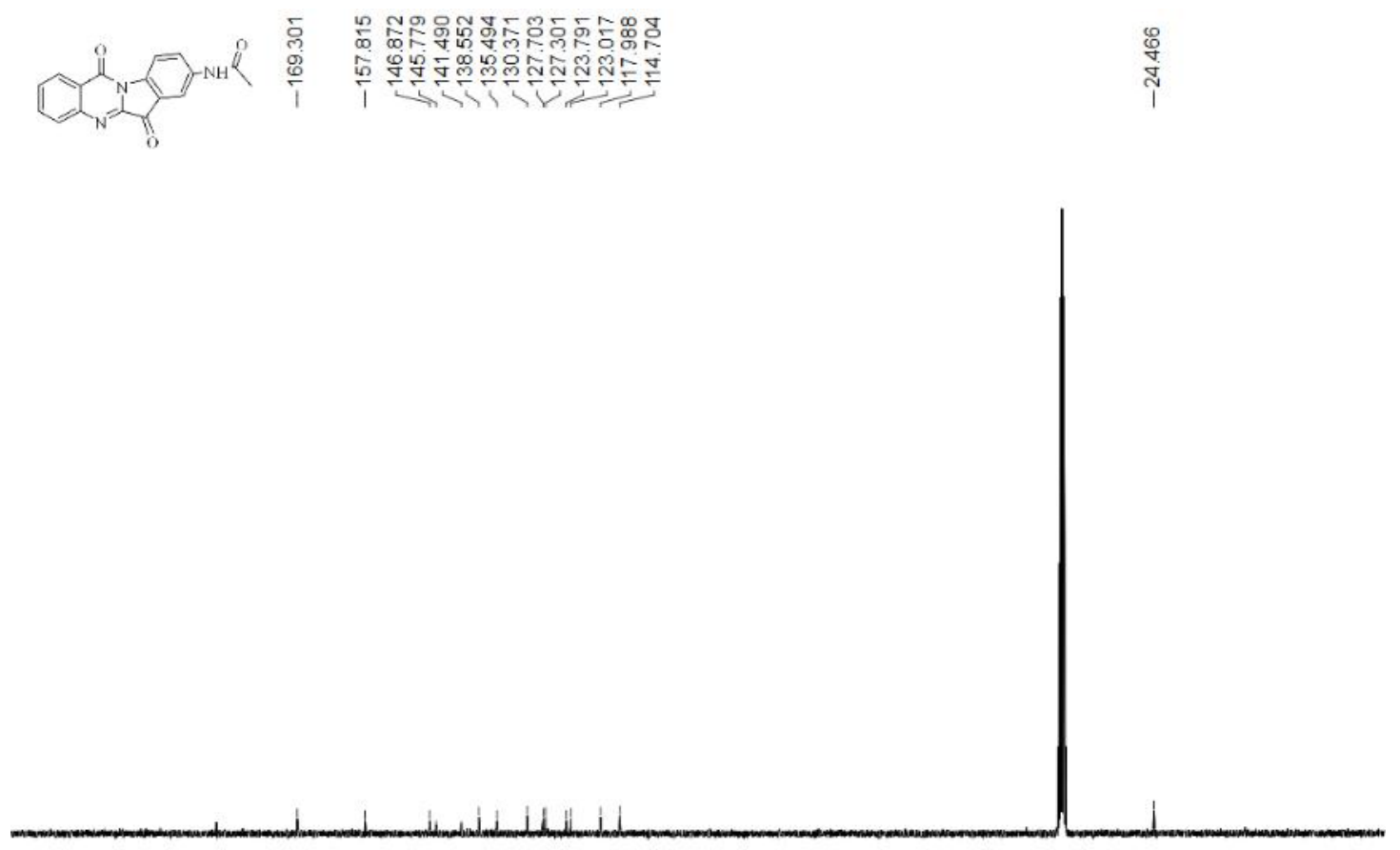

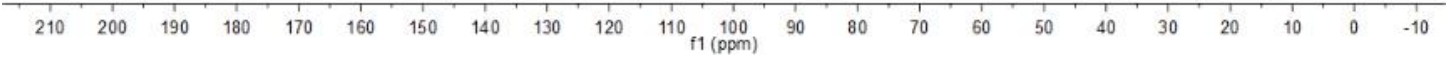

${ }^{13} \mathrm{C}$ NMR spectra of $5 \mathrm{a}$ 


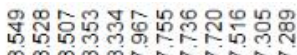

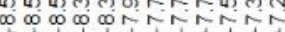
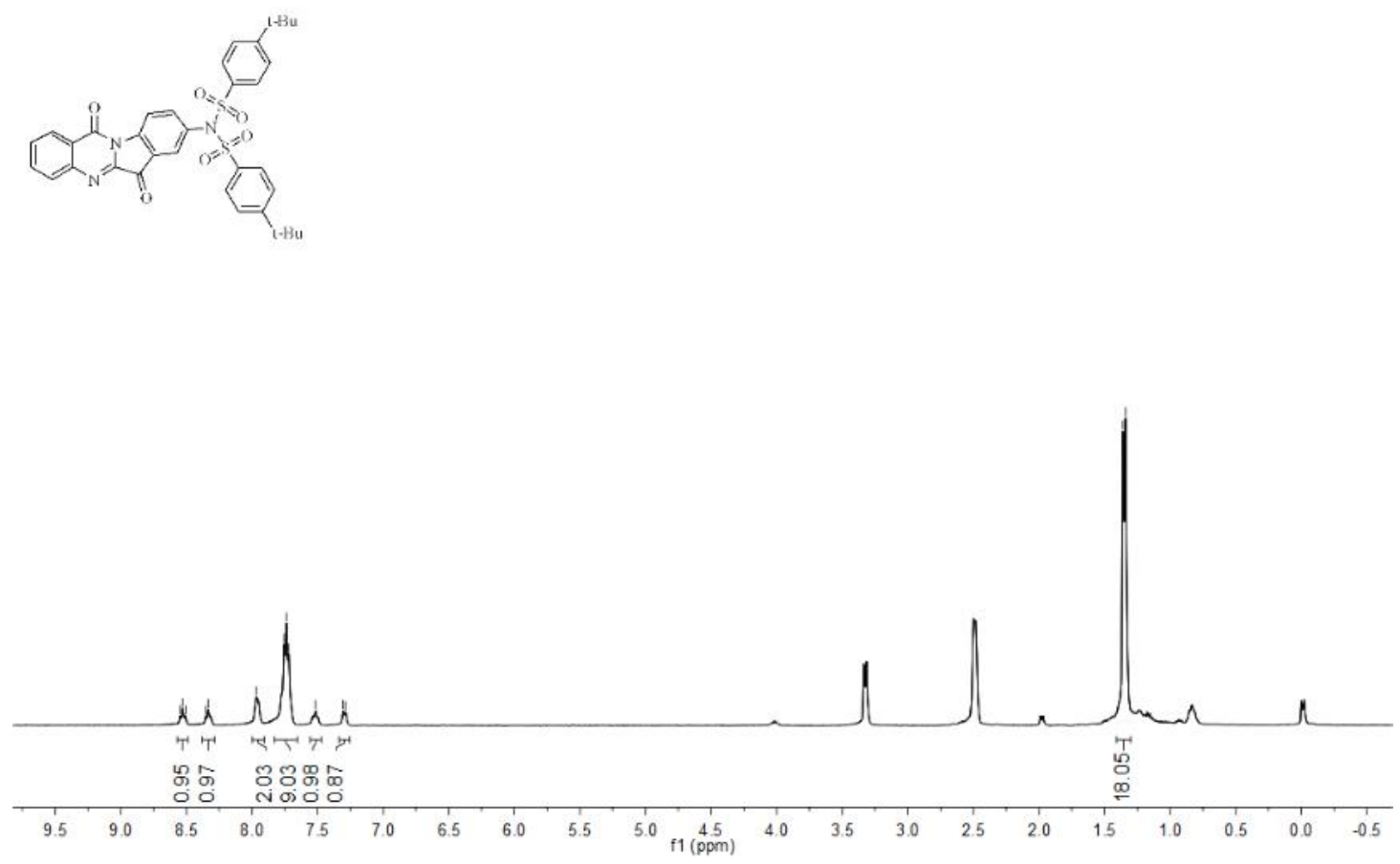

${ }^{1} \mathrm{H}$ NMR spectra of $5 b$

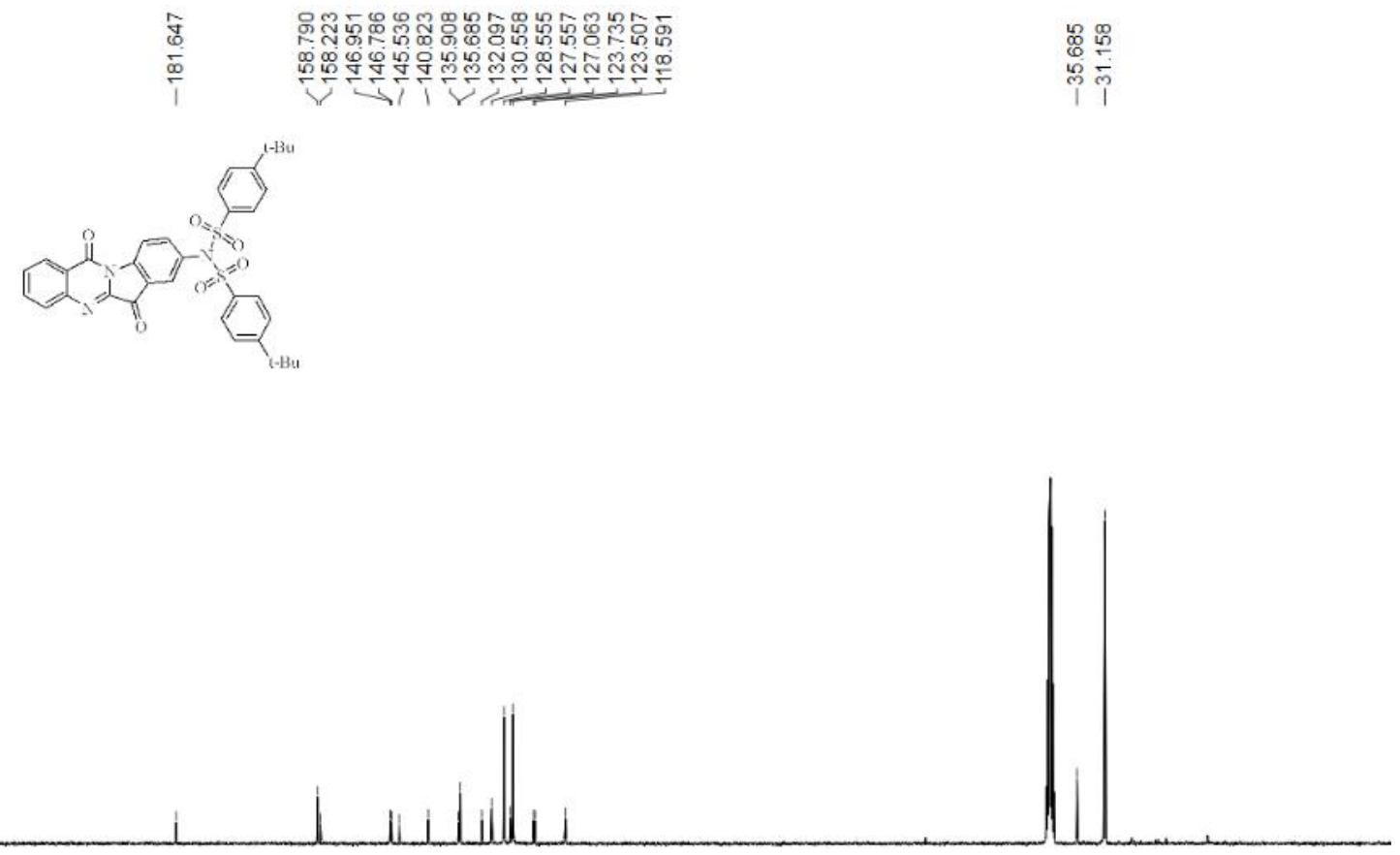

$\begin{array}{llllllllllllllllllllllllllll}1 & 200 & 190 & 180 & 170 & 160 & 150 & 140 & 130 & 120 & 110 & \begin{array}{c}100 \\ \mathrm{f} 1(\mathrm{ppm})\end{array} & 90 & 80 & 70 & 60 & 50 & 40 & 30 & 20 & 10 & 0 & -10\end{array}$

${ }^{13} \mathrm{C}$ NMR spectra of $5 \mathrm{~b}$ 

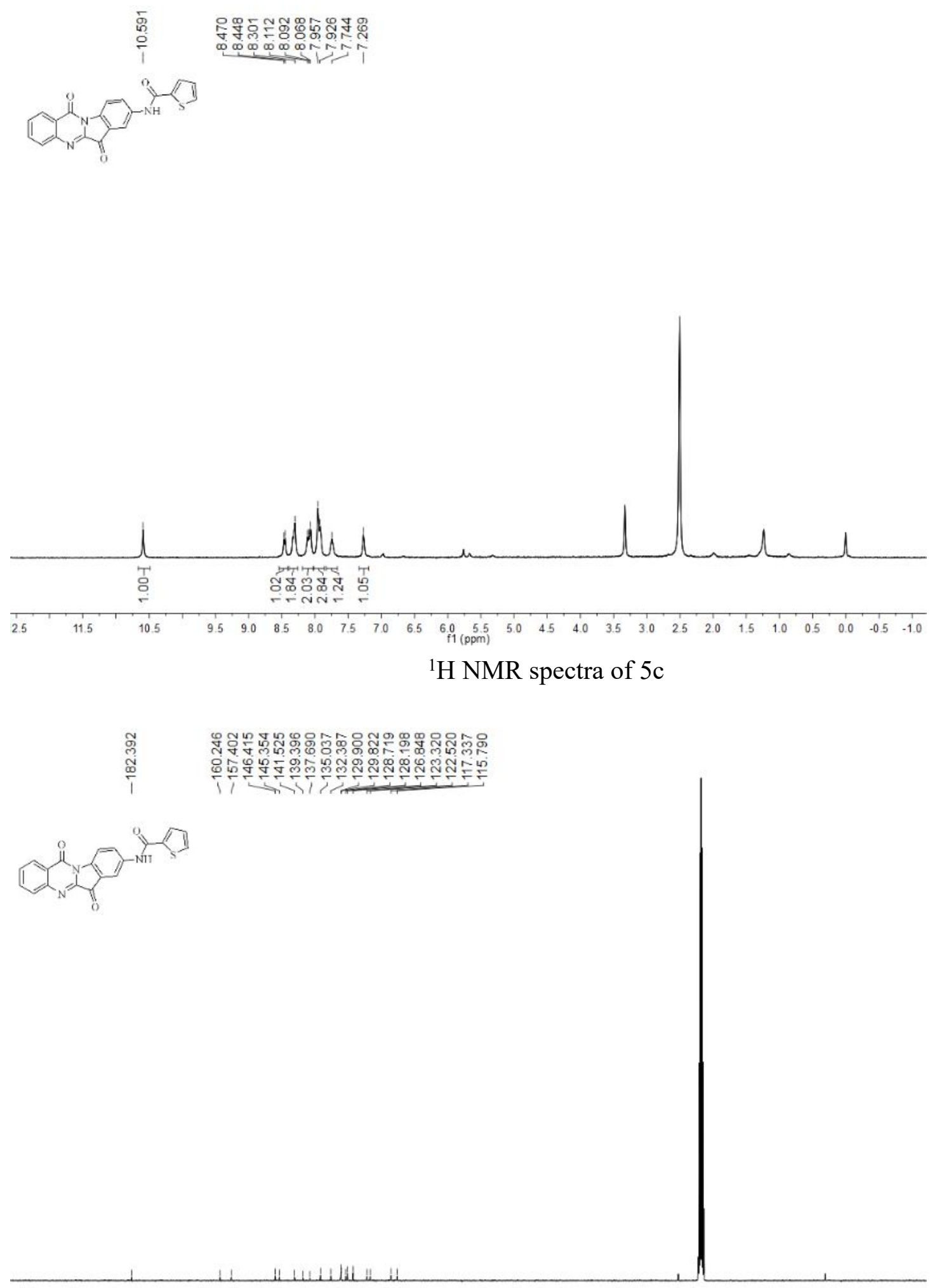

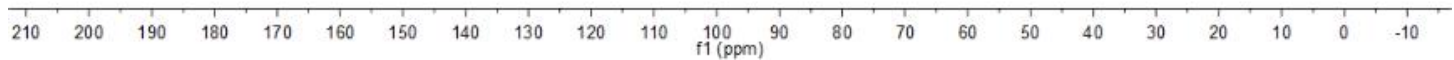
${ }^{13} \mathrm{C}$ NMR spectra of $5 \mathrm{c}$ 


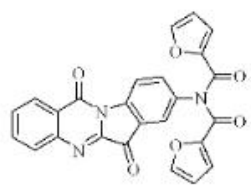
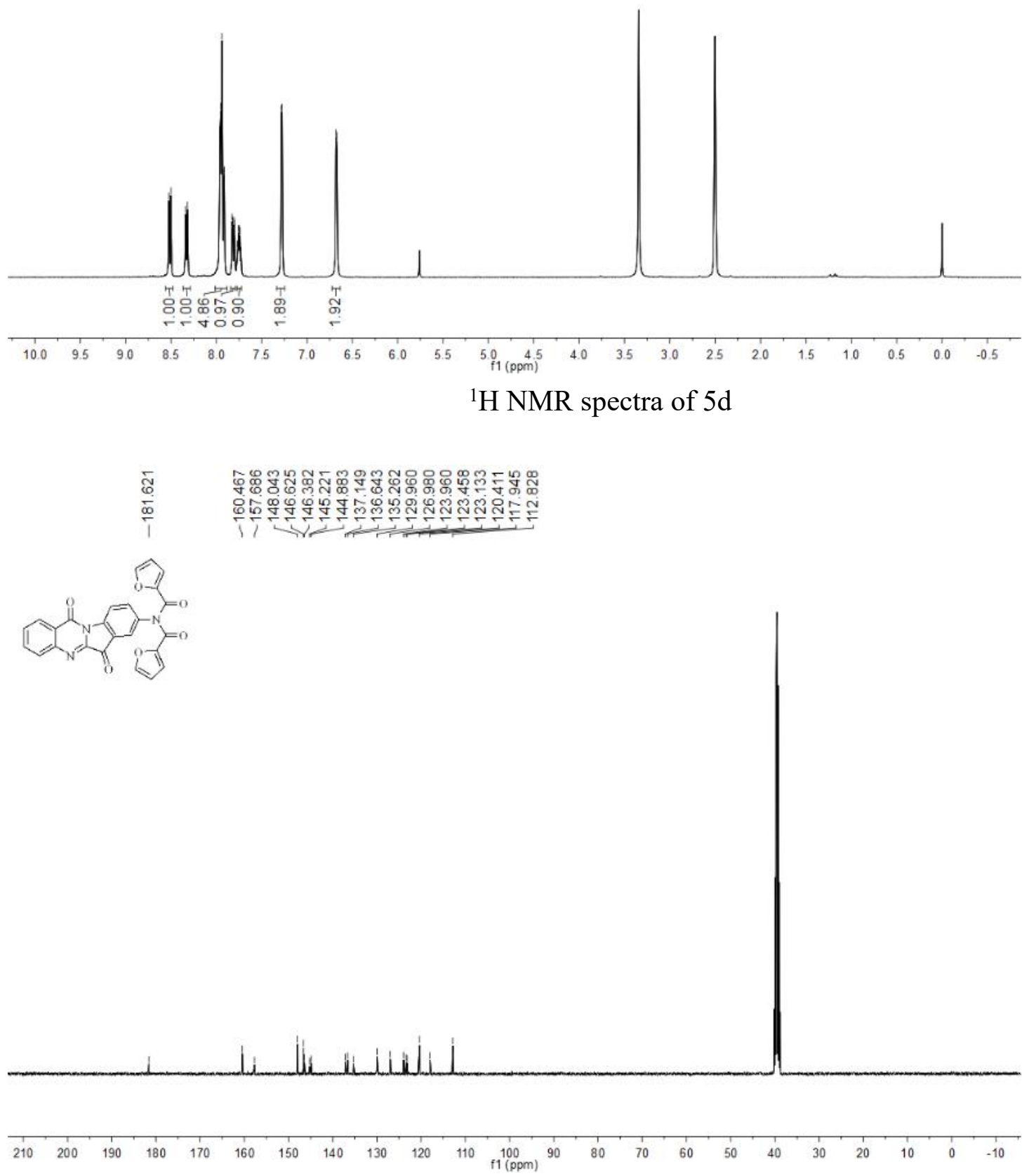

${ }^{13} \mathrm{C}$ NMR spectra of $5 \mathrm{~d}$ 


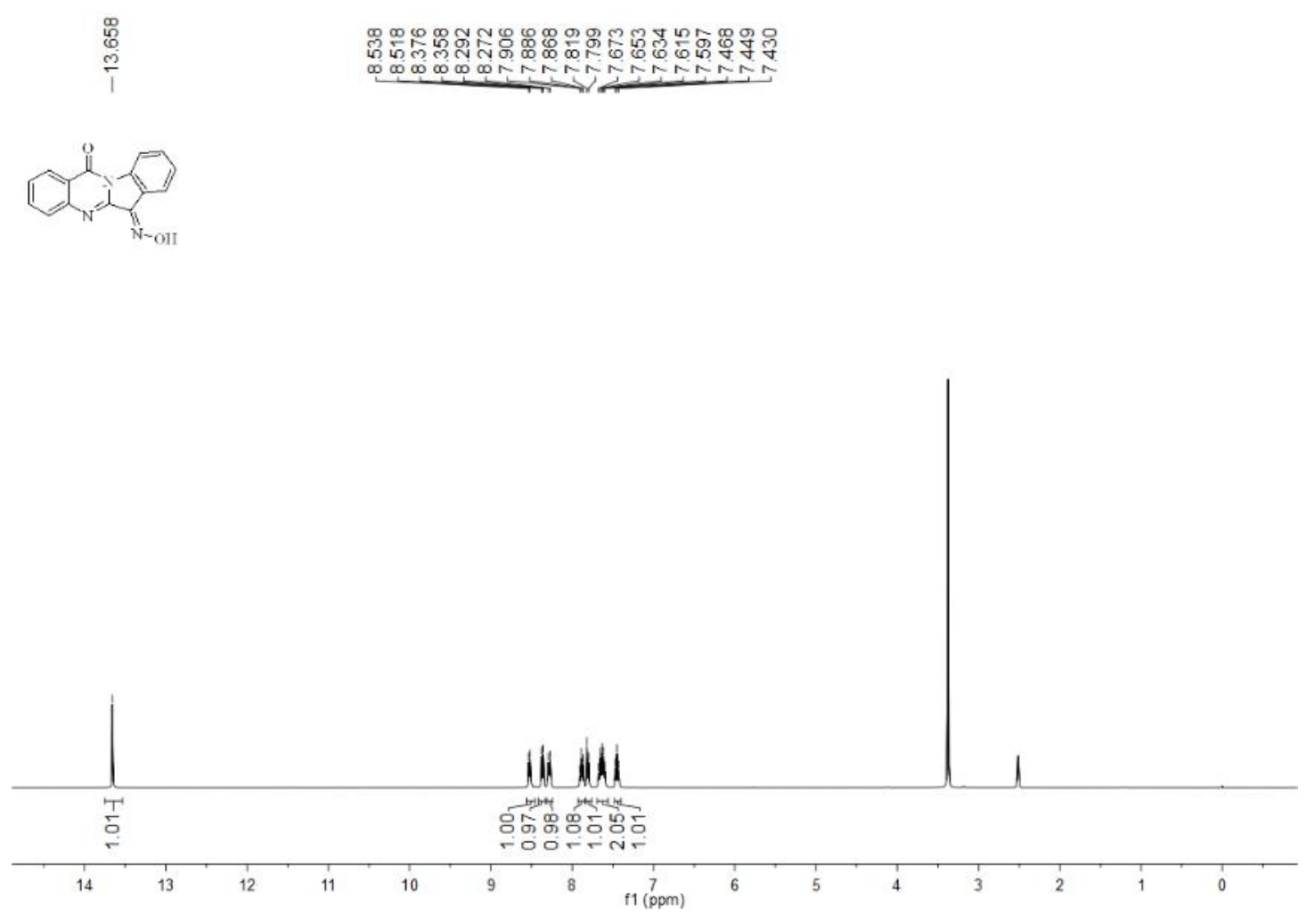

${ }^{1} \mathrm{H}$ NMR spectra of $8 \mathrm{a}$
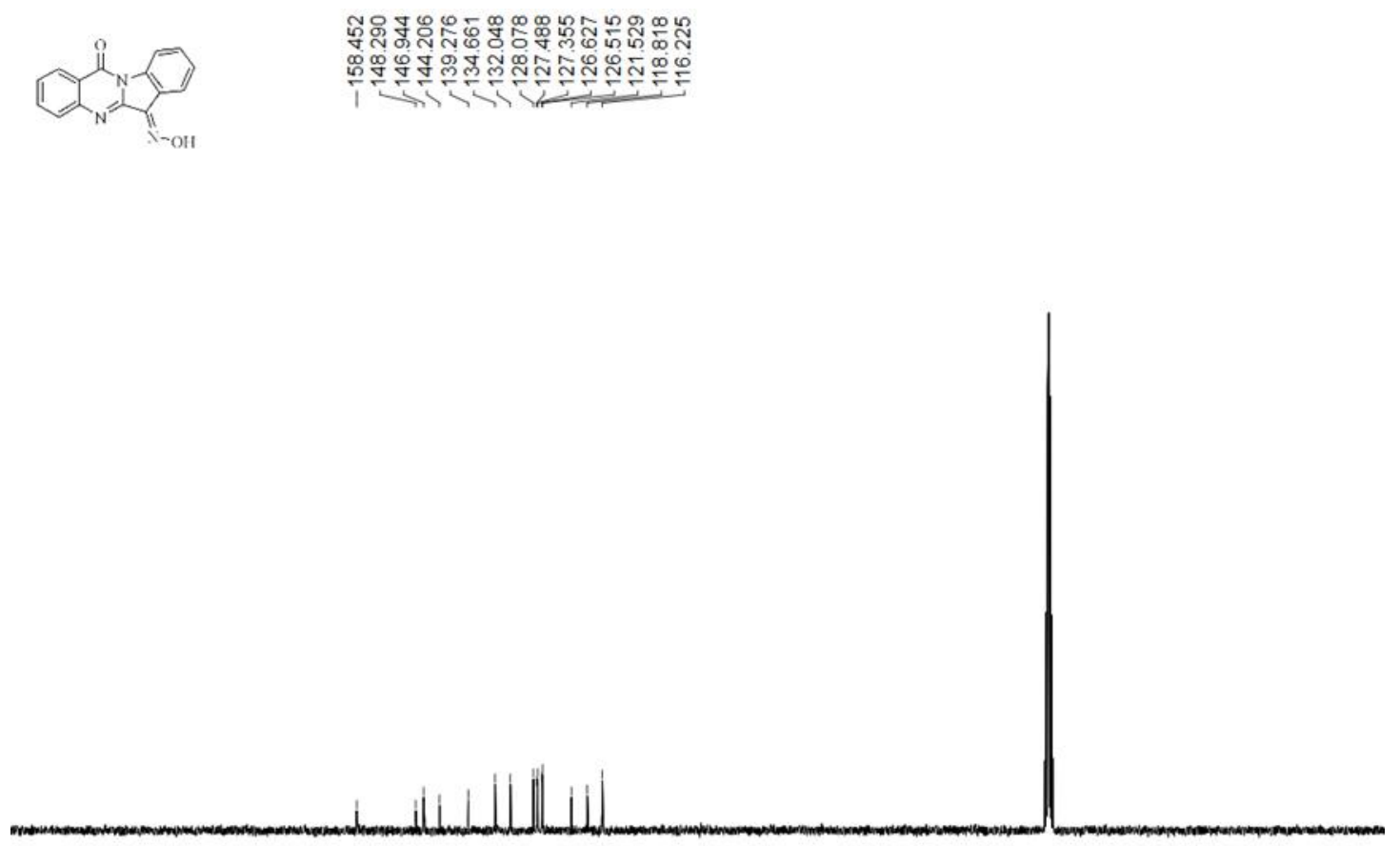

$\begin{array}{llllllllllllllllllllllllll}210 & 200 & 190 & 180 & 170 & 160 & 150 & 140 & 130 & 120 & 110 & 100 & 10 & 80 & 70 & 60 & 50 & 40 & 30 & 20 & 10 & 0 & -10\end{array}$

${ }^{13} \mathrm{C}$ NMR spectra of $8 \mathrm{a}$ 


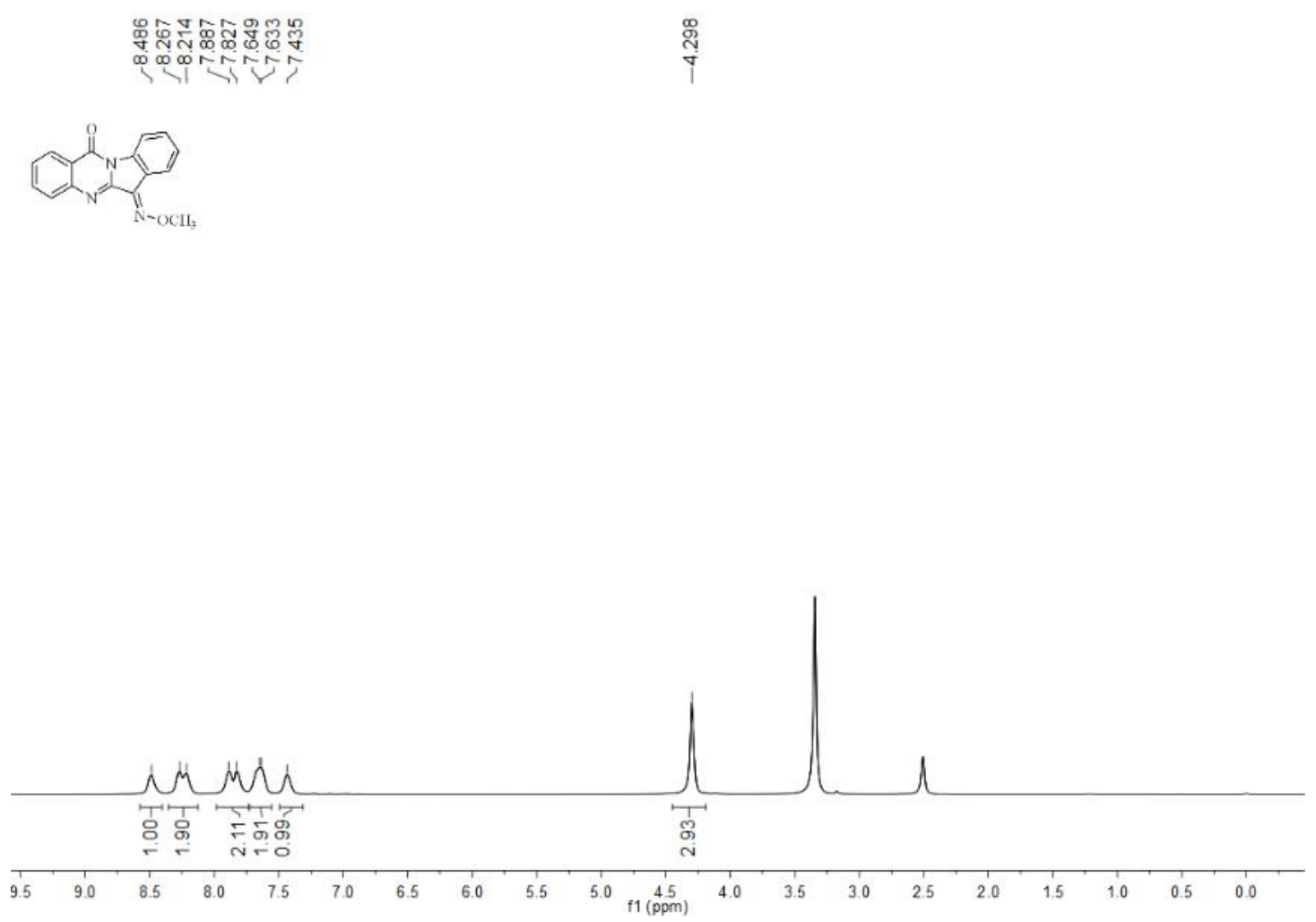

${ }^{1} \mathrm{H}$ NMR spectra of $8 \mathrm{~b}$

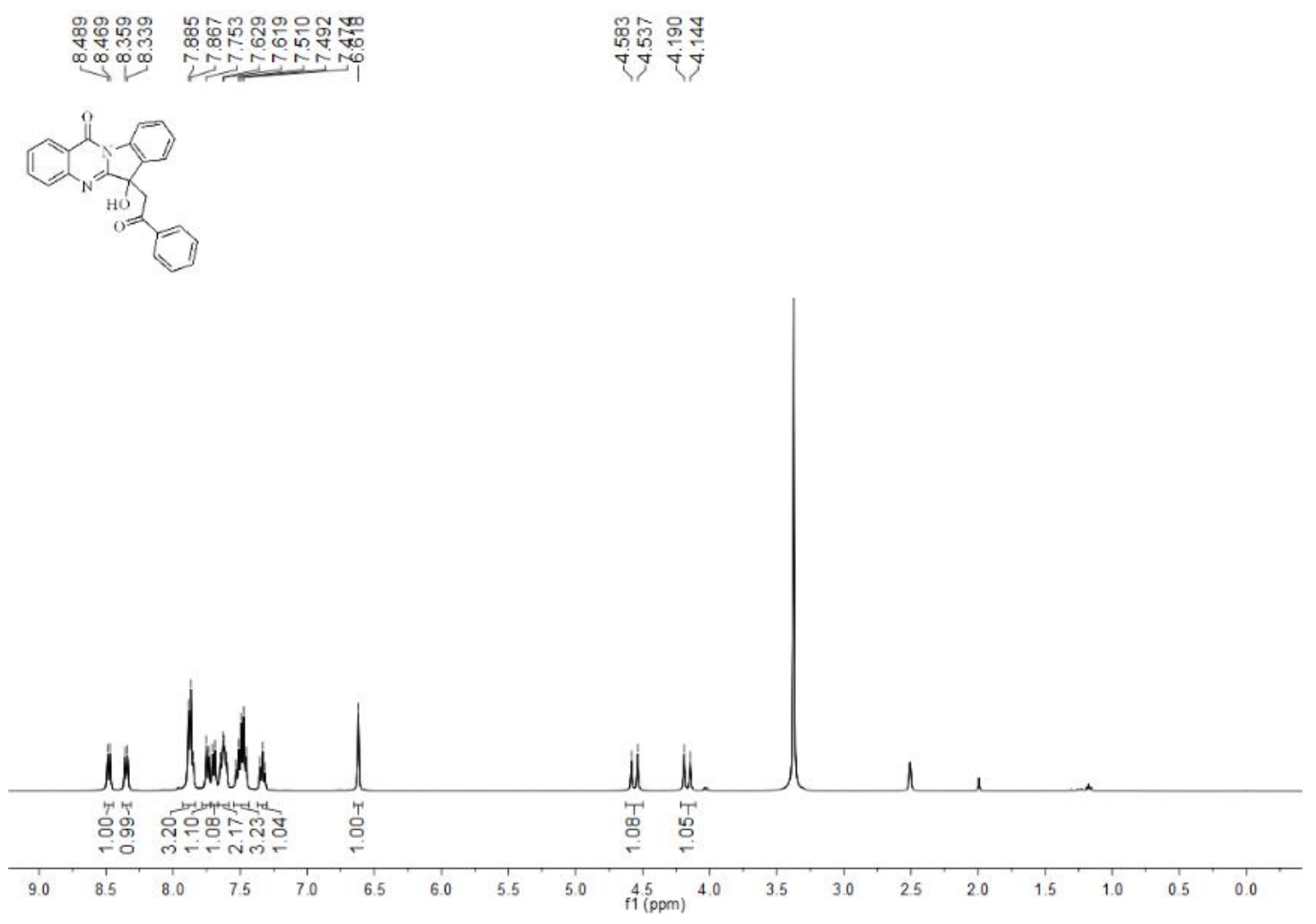

${ }^{1} \mathrm{H}$ NMR spectra of 10a 


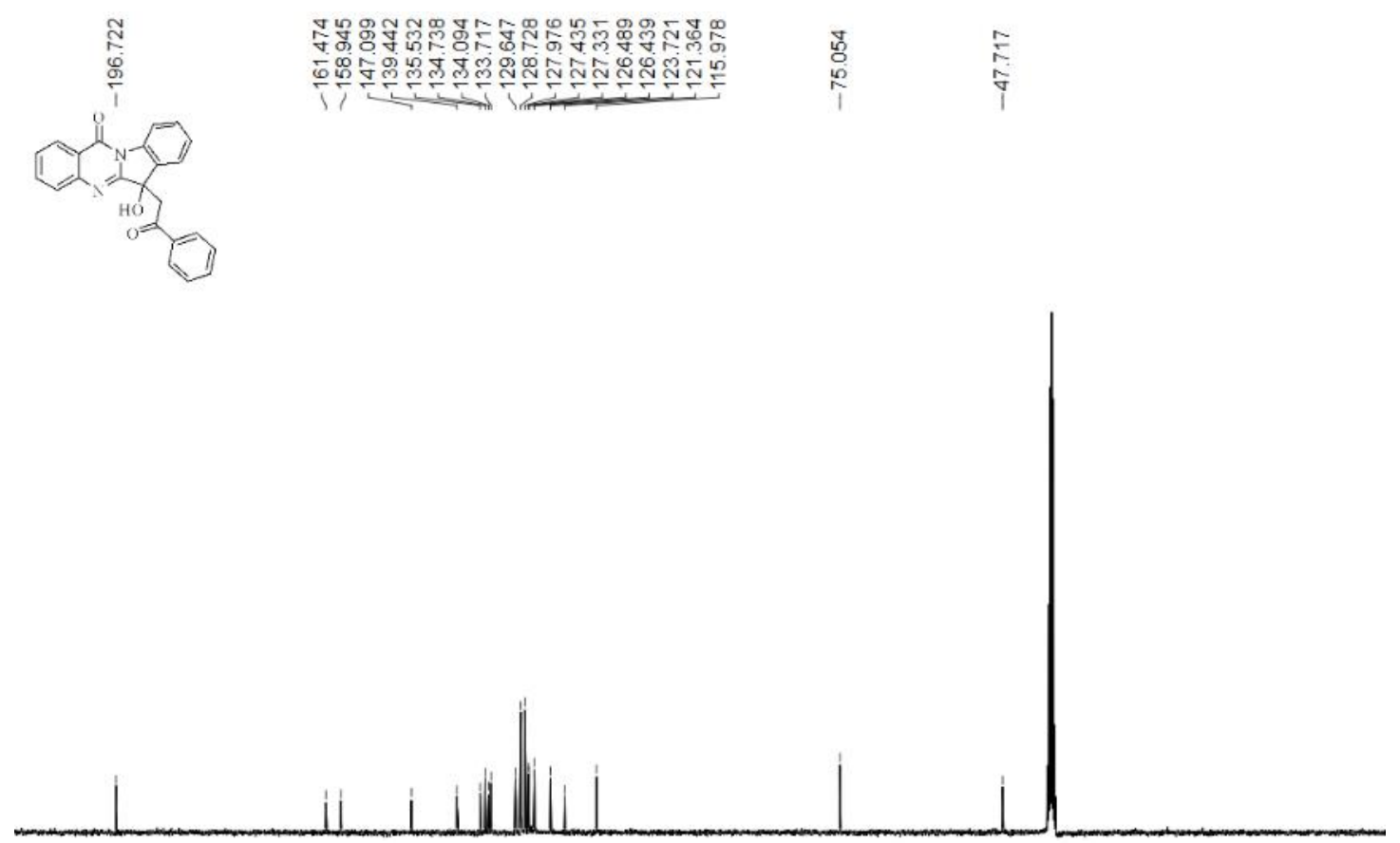

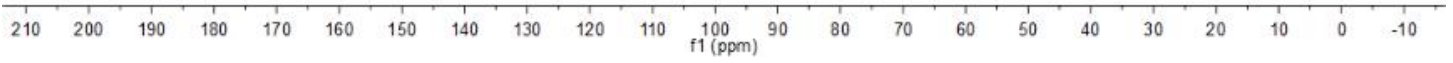

${ }^{13} \mathrm{C}$ NMR spectra of $10 \mathrm{a}$

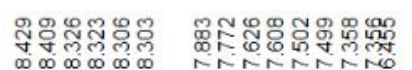

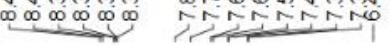

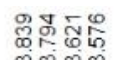

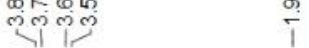

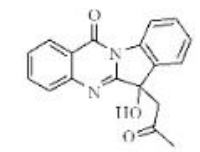

ֻั

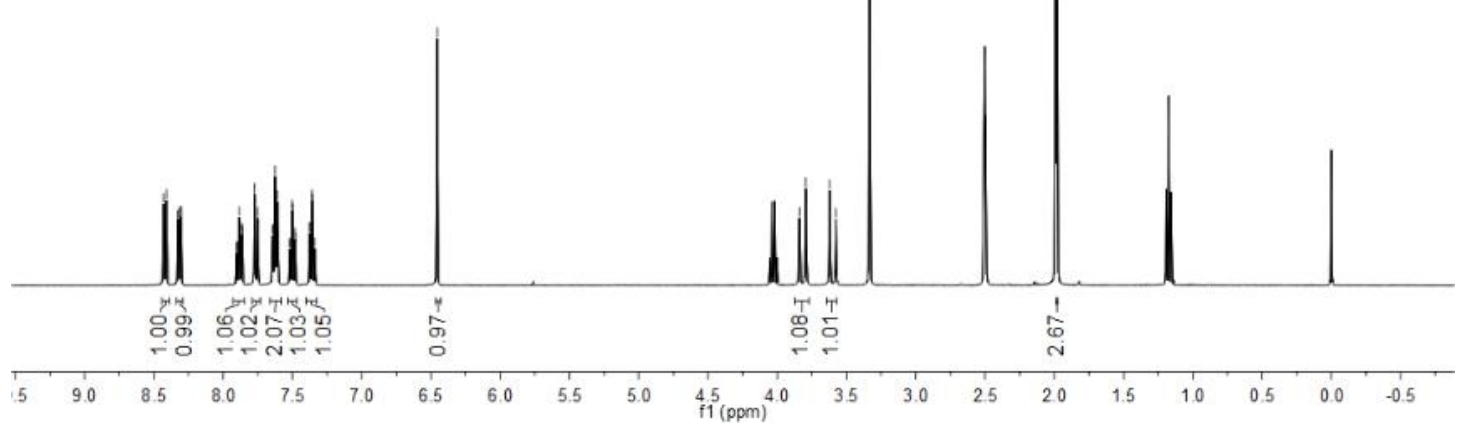

${ }^{1} \mathrm{H}$ NMR spectra of $10 \mathrm{~b}$ 


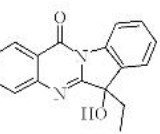

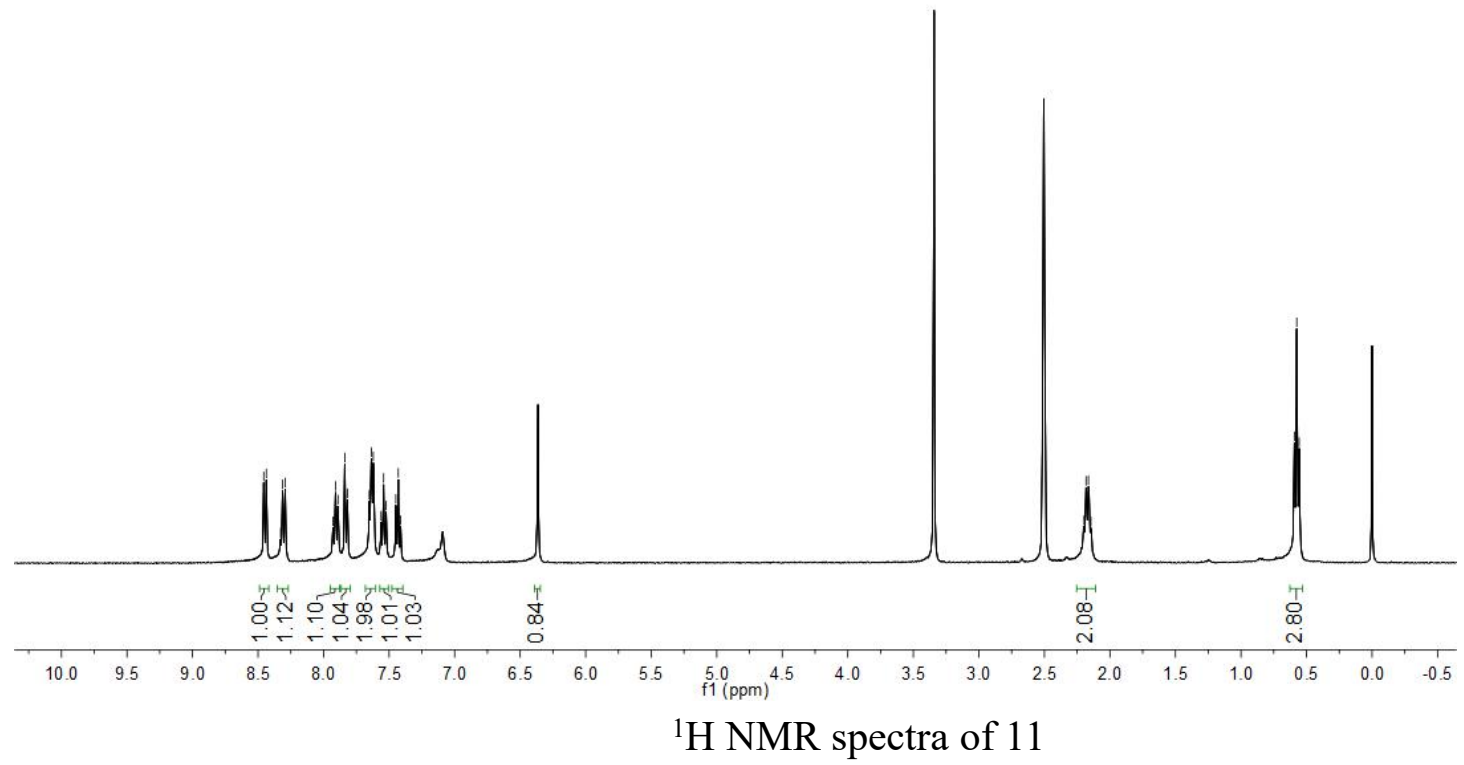<smiles></smiles>

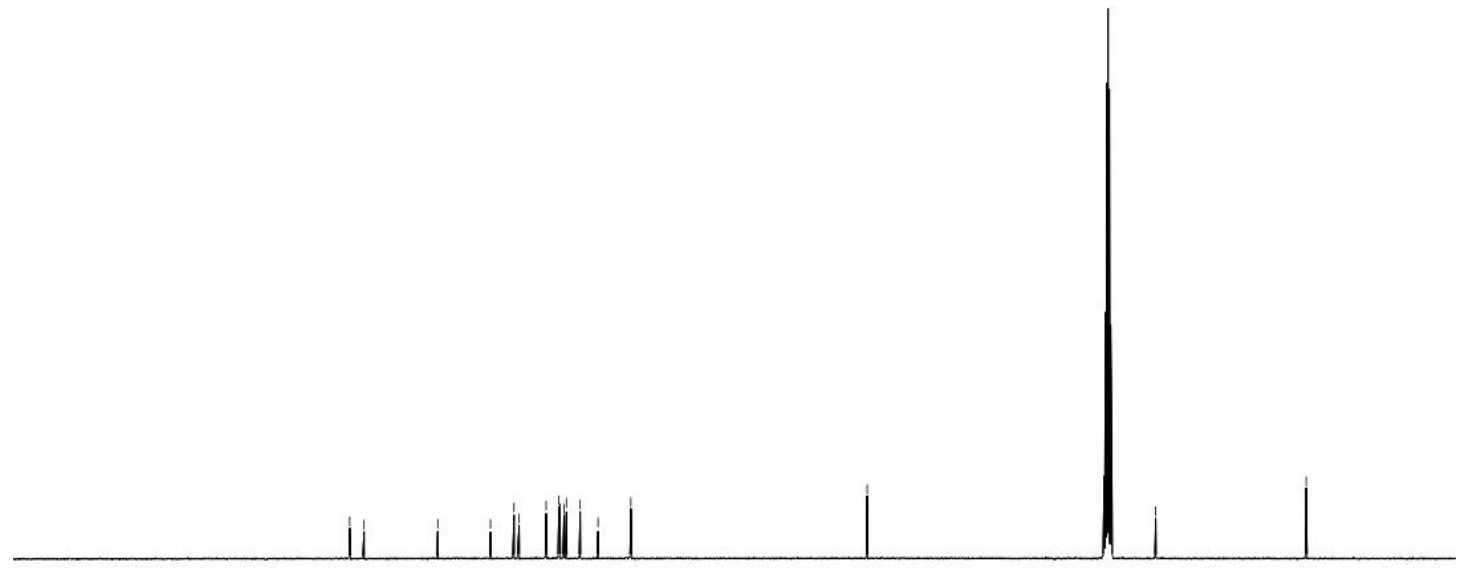

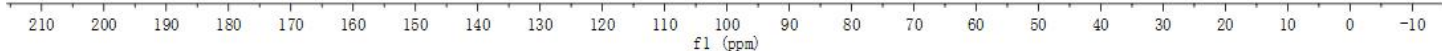
${ }^{13} \mathrm{C}$ NMR spectra of 11 


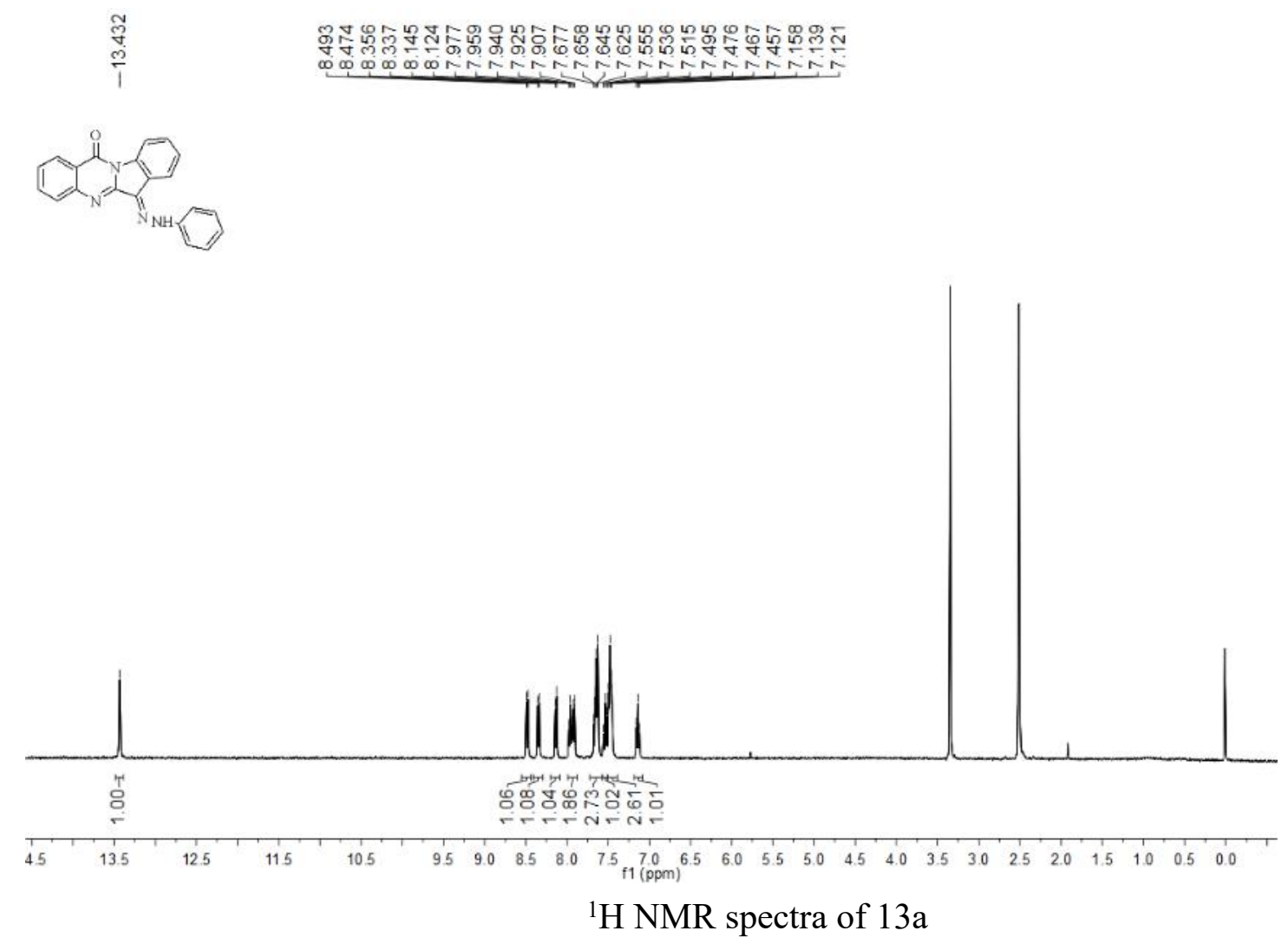

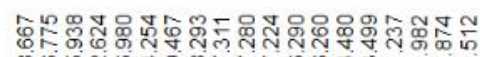

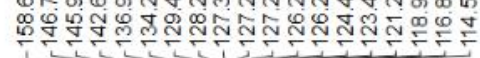
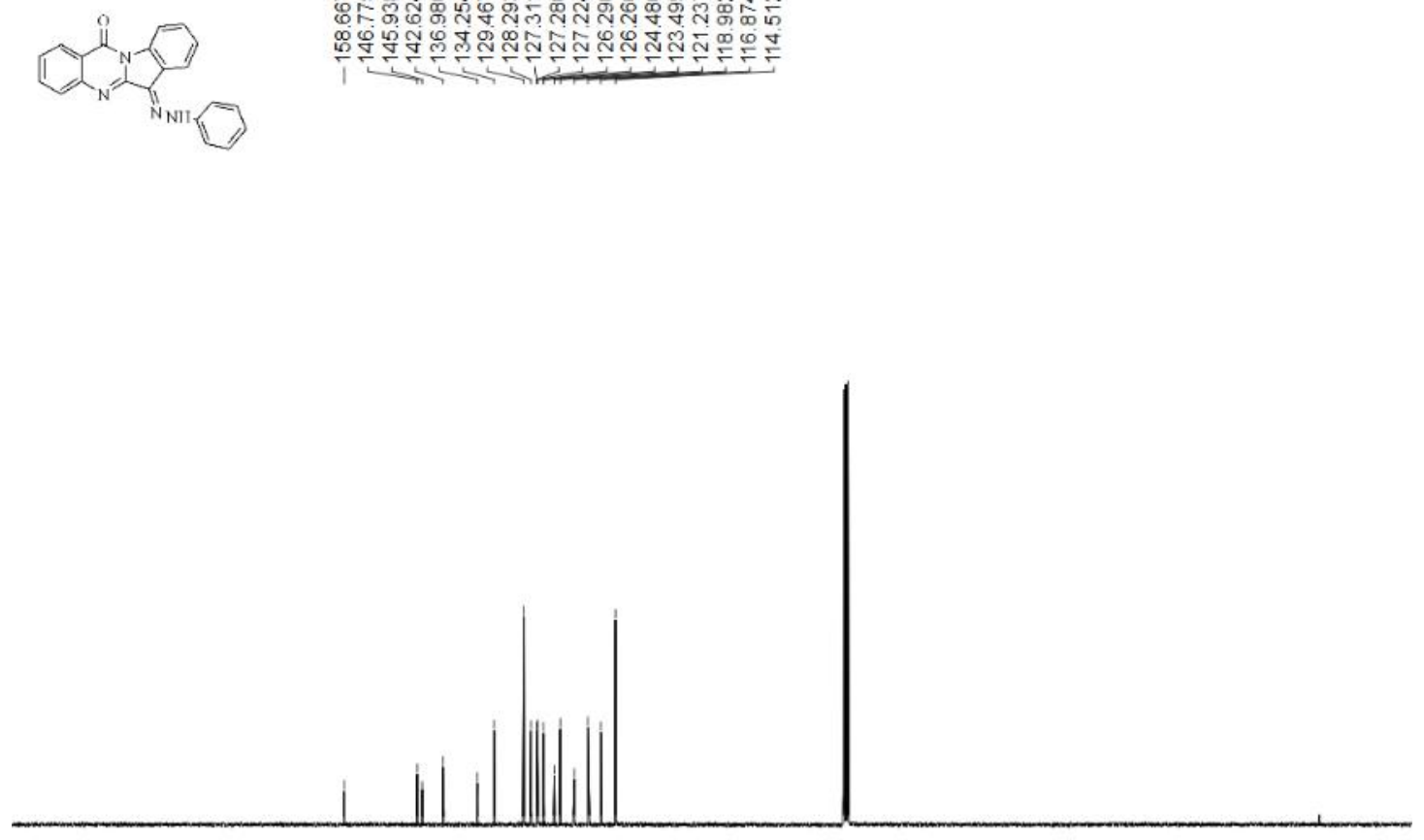

\begin{tabular}{llllllllllllllllllllllllllll}
\hline 210 & 200 & 190 & 180 & 170 & 160 & 150 & 140 & 130 & 120 & 110 & $\begin{array}{c}100 \\
\mathrm{f} 1(\mathrm{pm})\end{array}$ & 90 & 80 & 70 & 60 & 50 & 40 & 30 & 20 & 10 & 0 & -10
\end{tabular}

${ }^{13} \mathrm{C}$ NMR spectra of $13 \mathrm{a}$ 

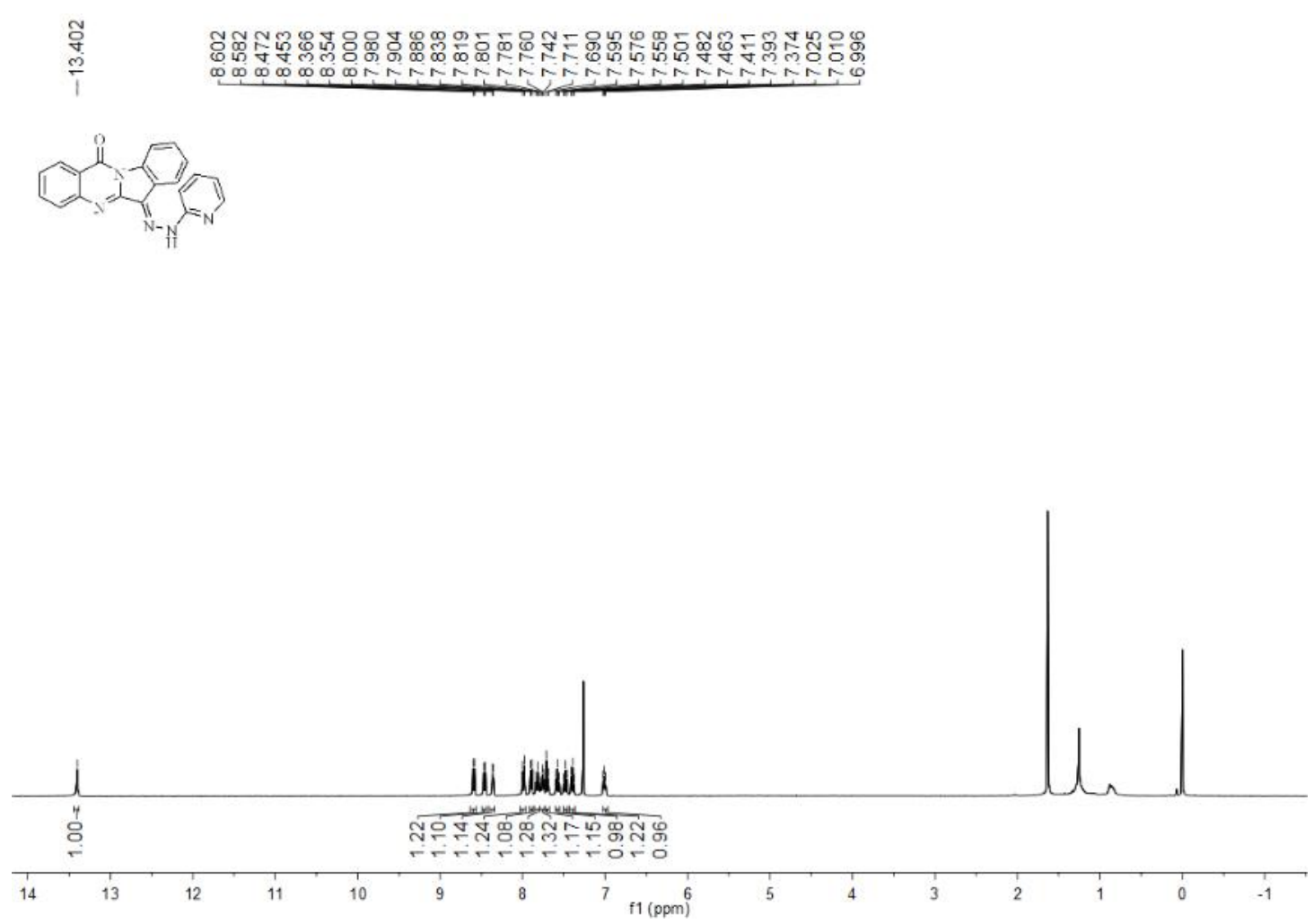

${ }^{1} \mathrm{H}$ NMR spectra of $13 \mathrm{~b}$

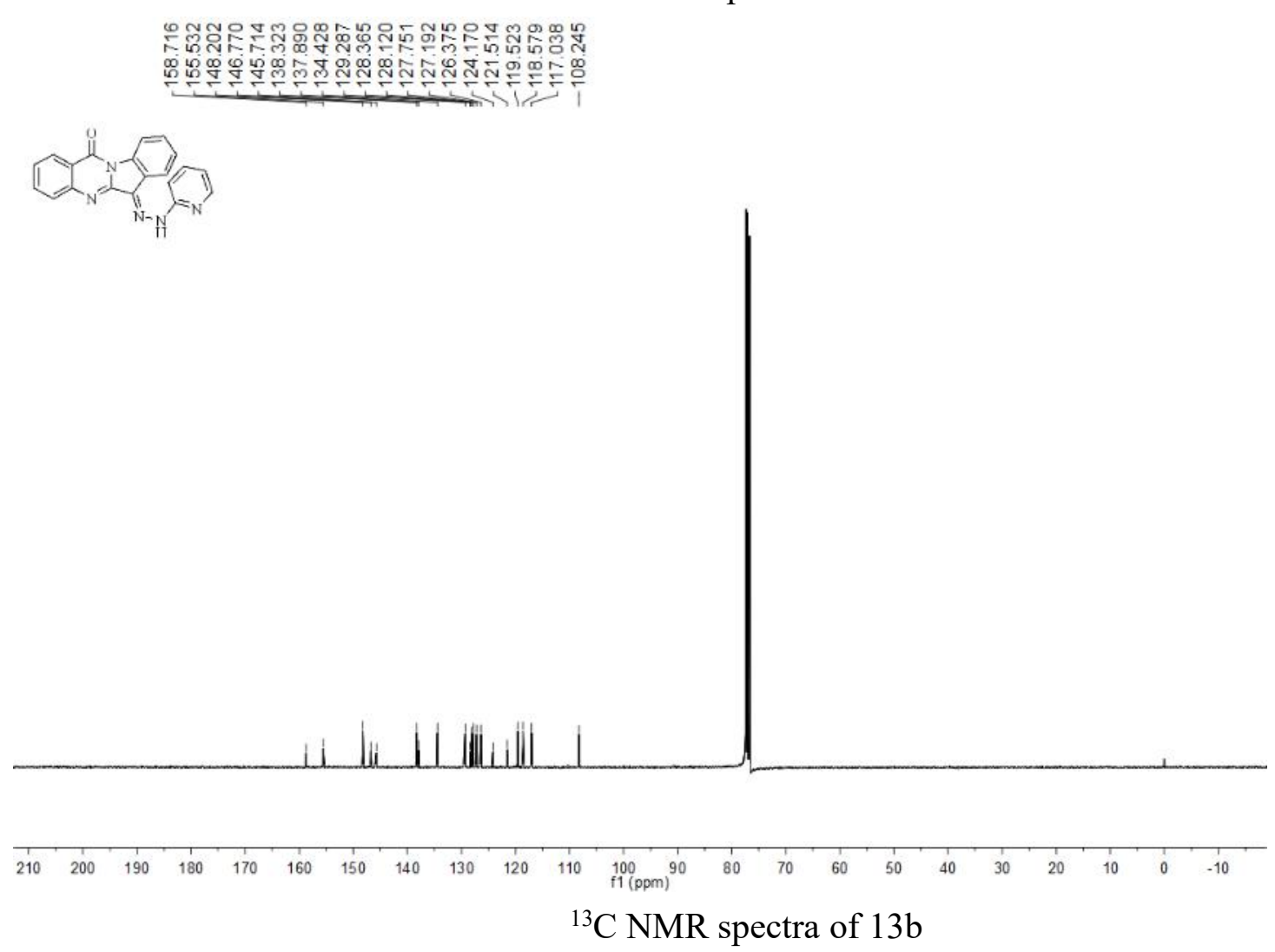



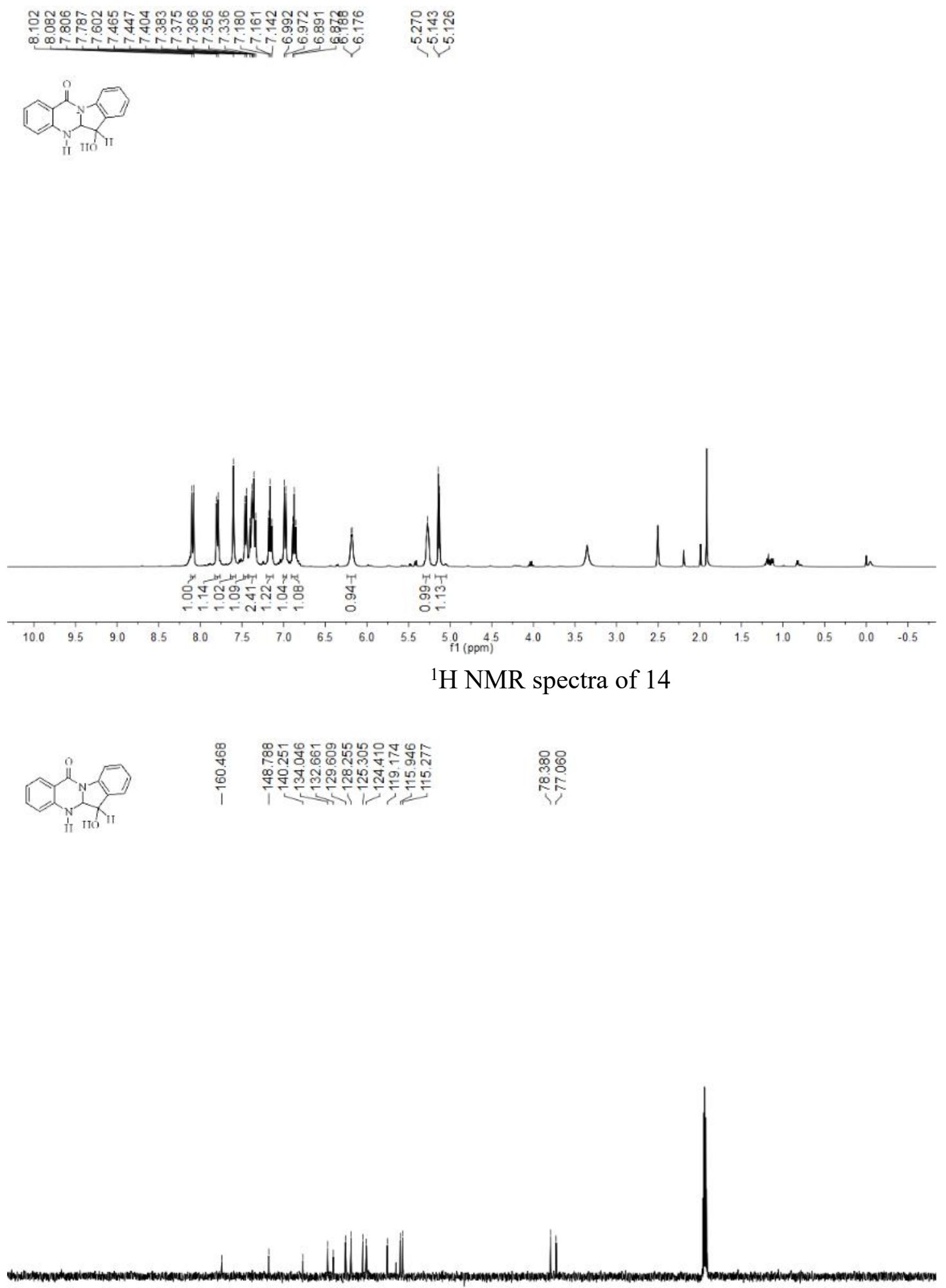

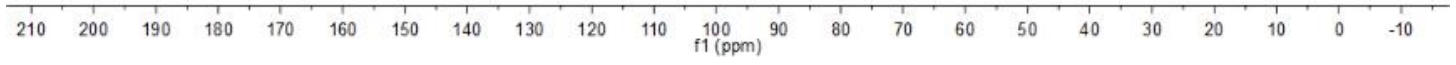

${ }^{13} \mathrm{C}$ NMR spectra of 14 

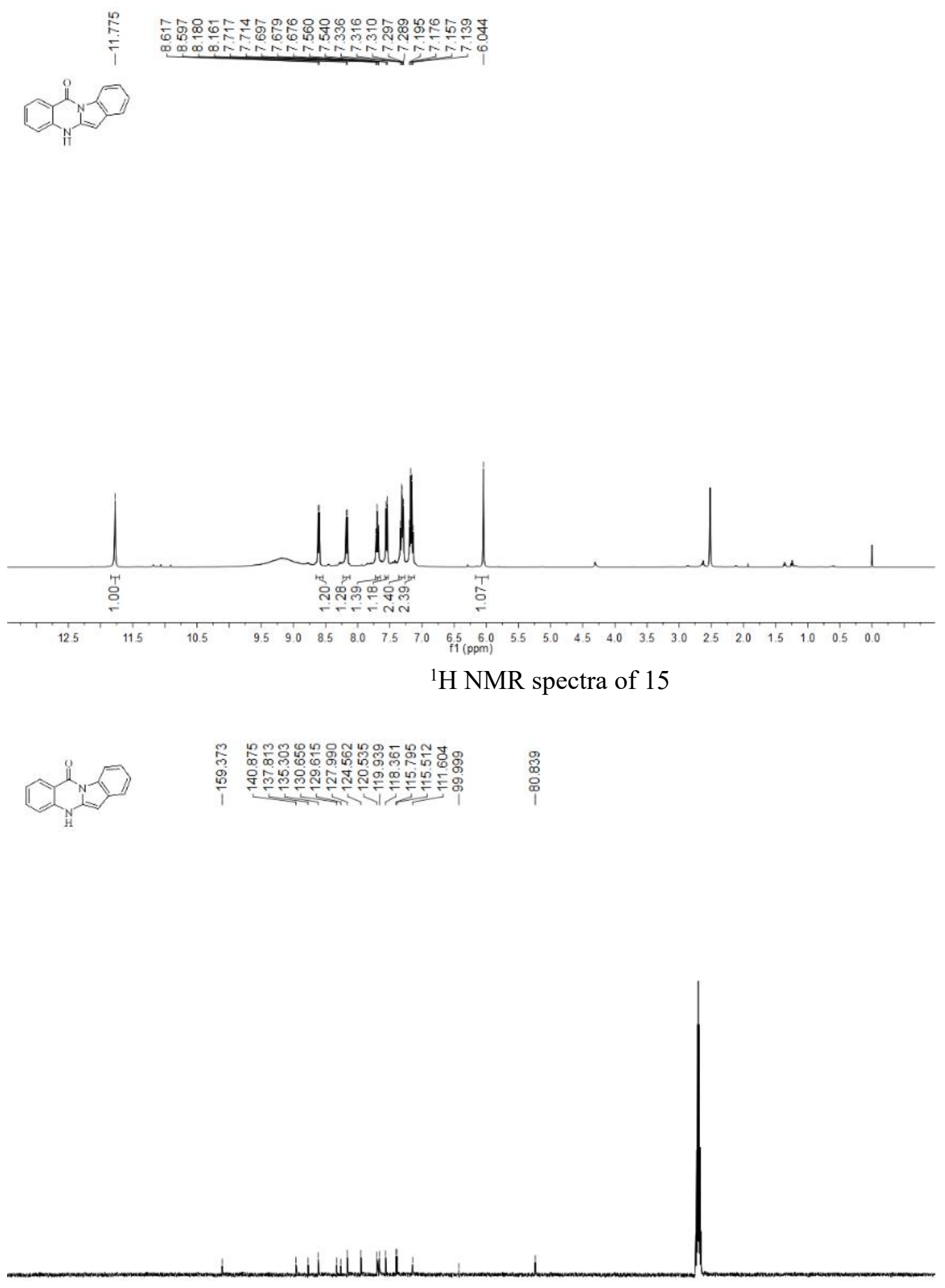

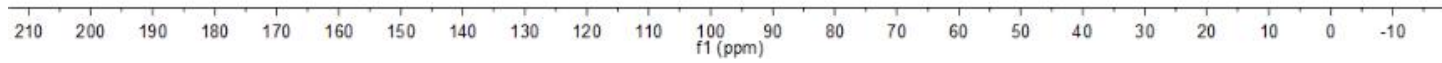

${ }^{13} \mathrm{C}$ NMR spectra of 15 

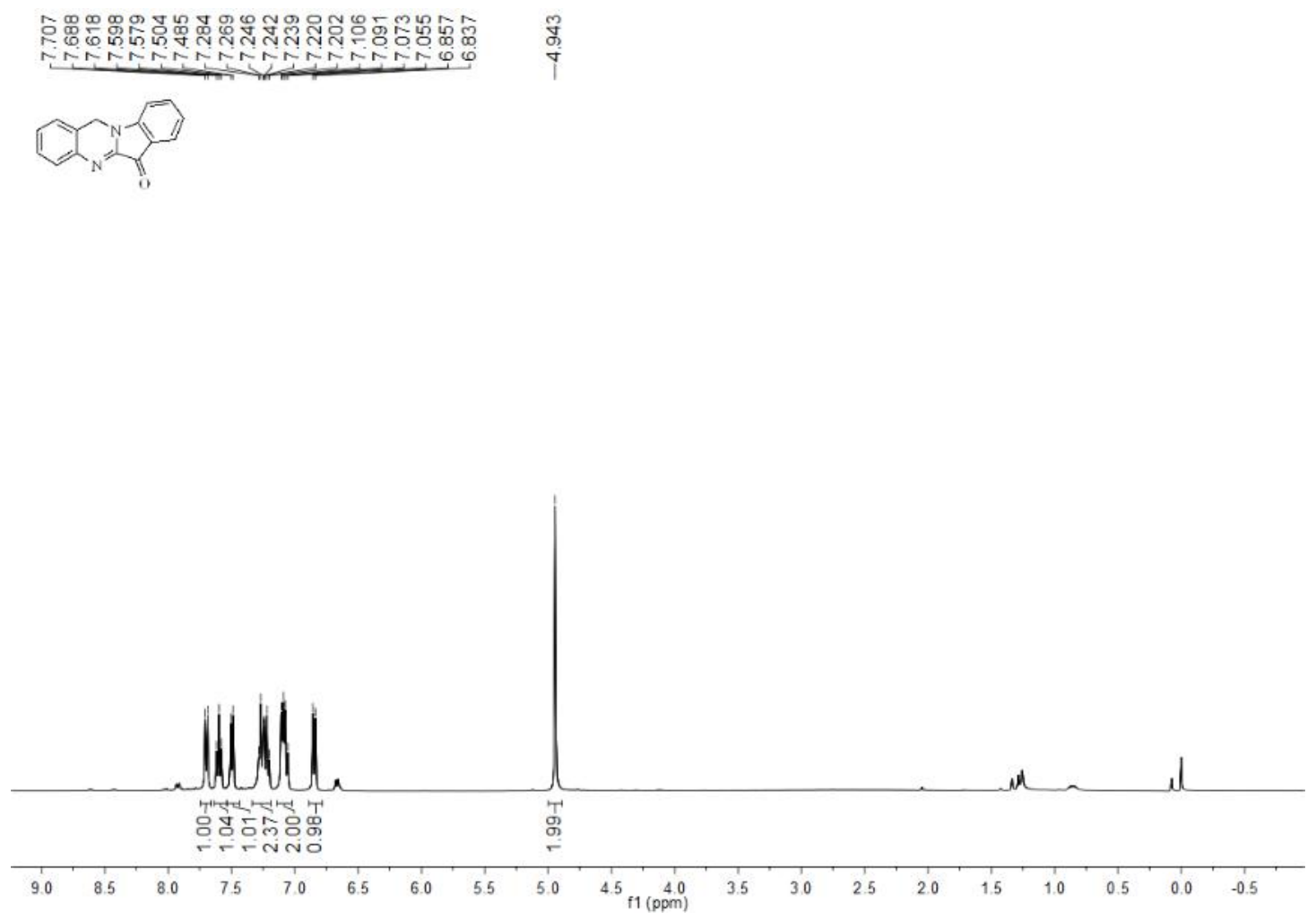

${ }^{1} \mathrm{H}$ NMR spectra of 16
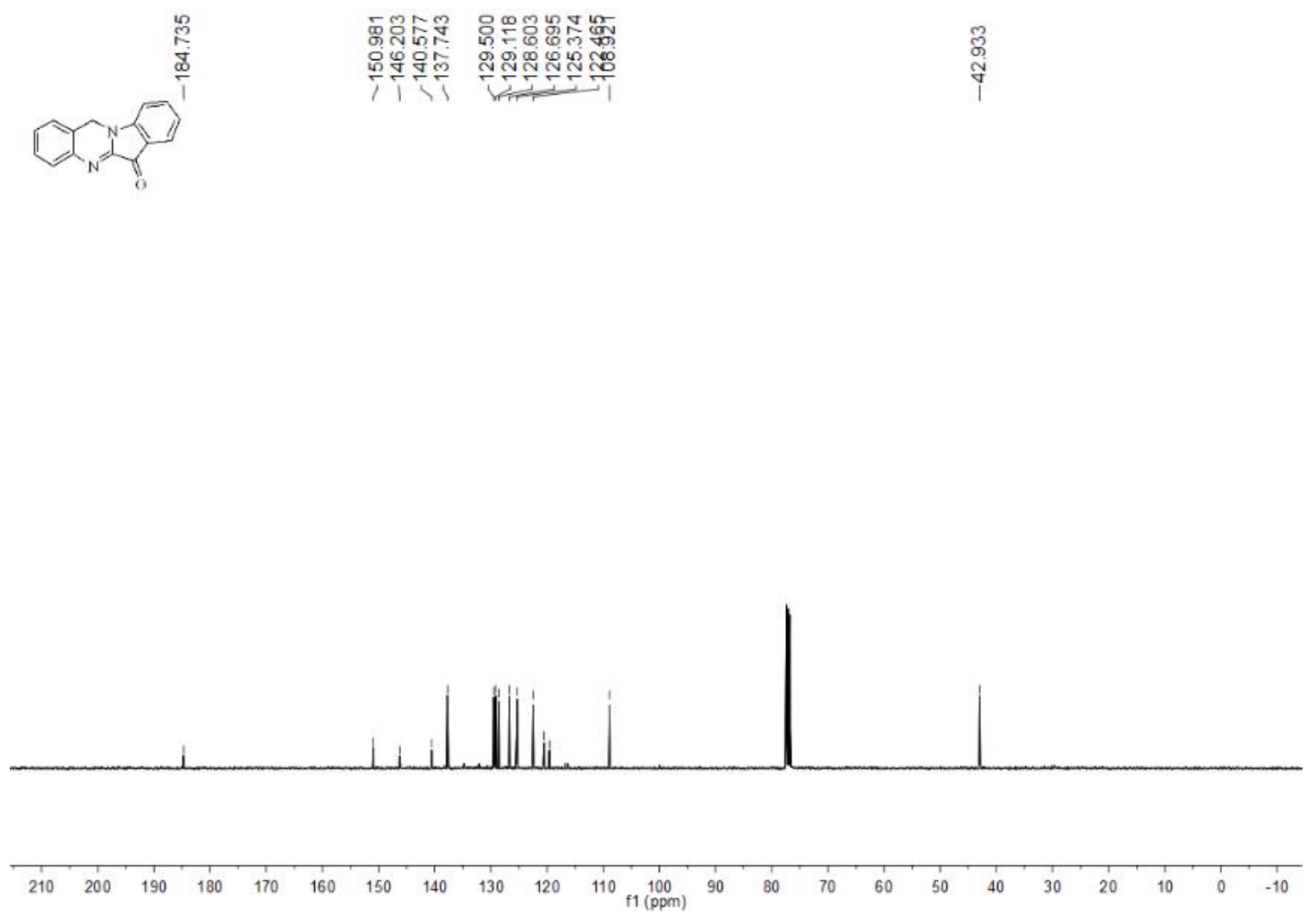

${ }^{13} \mathrm{C}$ NMR spectra of 16 


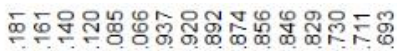

政

(1)

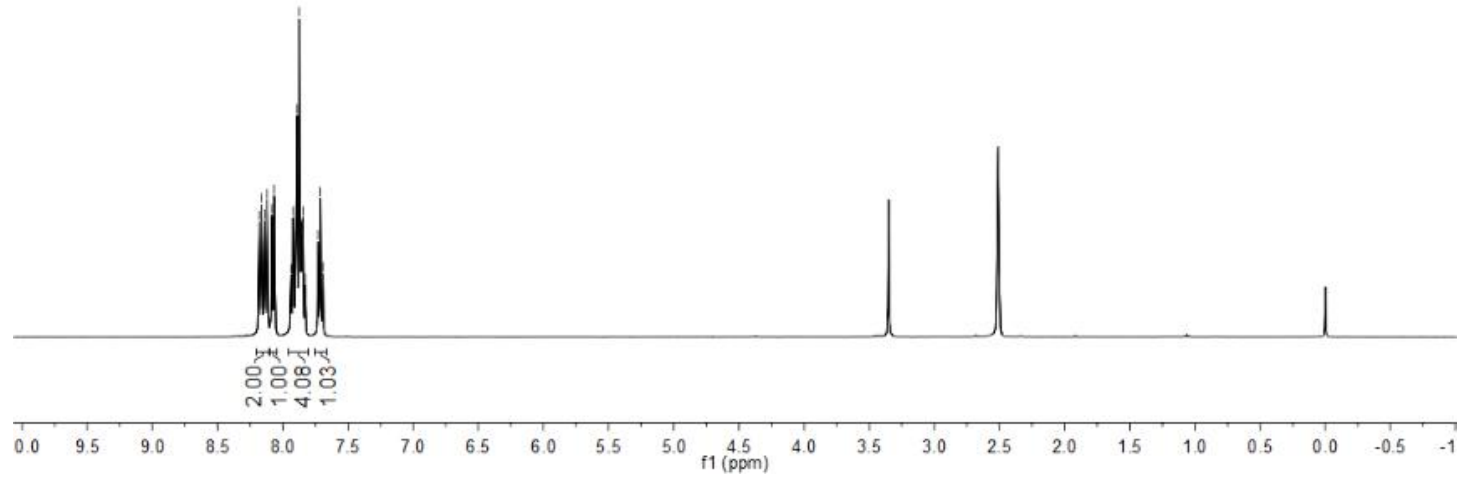

${ }^{1} \mathrm{H}$ NMR spectra of 19 